\title{
EL PAGO DE LA MULTA Y LA LEY 1709 DE 2014: ANALISIS DE LA LIBERTAD CONDICIONAL Y LOS SISTEMAS DE VIGILANCIA ELECTRÓNICA ANTES DEL TRÁNSITO LEGISLATIVO ${ }^{1}$
}

\section{Norberto Hernandez Jimenez ${ }^{2}$}

\section{Resumen}

En el presente texto se analiza la situación del condenado insolvente frente a la exigencia - eliminada por la ley 1709 de 2014 -, del pago de la multa para resultar beneficiado de la libertad condicional y los sistemas de vigilancia electrónica como sustitutivos de la prisión. Para esto se examina la aplicación de las sentencias C-185/11 y T309/12 en sede de los Juzgados de Ejecución de Penas y Medidas de Seguridad de Bogotá y su corolario como solución a la situación de hacinamiento carcelario.

Palabras clave: Condenado insolvente, multa, libertad condicional, vigilancia electrónica, hacinamiento.

\section{INTRODUCCIÓN}

La Corte Constitucional en el año $1998^{3}$ declaró el estado de cosas inconstitucional en las prisiones colombianas tras considerar que las condiciones de hacinamiento impedían implementar el proyecto de resocialización a favor de los reclusos, vulnerándose su derecho a la vida digna, careciendo de servicios sanitarios, asistencia en salud y un lugar adecuado para pernoctar, viéndose obligados a dormir en el suelo e incluso en los baños, fomentando la propagación de enfermedades por las condiciones insalubres.

La sobrepoblación carcelaria tampoco permite separar a las personas que están siendo procesadas y que se encuentran privadas de su libertad con base en una medida de aseguramiento consistente en detención

\footnotetext{
${ }^{1}$ Artículo de reflexión realizado por el autor en desarrollo de su labor al interior del Grupo Conflicto, Derecho y Sociedad de la Universidad de los Andes y la culminación del trabajo de campo bajo la metodología de análisis de casos.

${ }^{2}$ Doctorando en Derecho de la Universidad de los Andes. Coordinador del Grupo de Prisiones de la Universidad de los Andes y Conjuez del Tribunal Superior de Florencia (Caqueta) - Sala Penal. E-mail: n.hernandez29@uniandes.edu.co

${ }^{3}$ Sentencia T-153/98, M.P. Eduardo Cifuentes Muñoz. Nota: Las referencias que dentro de este texto se hagan a las providencias precedidas por los literales $\mathrm{C}$ - y T- corresponden a sentencias de constitucionalidad y de tutela, respectivamente, proferidas por la Corte Constitucional, organismo perteneciente a la Rama Judicial del Poder Público en Colombia, Corporación a la que el constituyente primario le confió la guarda de la integridad y supremacía de la Carta Política. Las siglas M.P. se utilizan para designar al Magistrado que elaboró la ponencia o el proyecto de fallo.
} 
preventiva -35.519 sindicados ${ }^{4}$-, de aquellas sobre las cuales pesa en su contra una sentencia condenatoria ejecutoriada -79.353 condenados $^{5}$-, ni tampoco separar en debida forma, a los miembros de la fuerza pública privados de la libertad de los demás reclusos, encontrándose mezclados ${ }^{6}$, lo que vulnera sus derechos al debido proceso, la vida y la integridad personal.

Estas circunstancias van en contravía, concretamente, de lo establecido en los artículos $7^{7}$ y $10^{8}$ del Pacto Internacional de Derechos Civiles y Políticos y se constituyen en una "flagrante violación de un abanico de derechos fundamentales de los internos en los centros penitenciarios colombianos, tales como la dignidad, la vida e integridad personal, los derechos a la familia, a la salud, al trabajo y a la presunción de inocencia, etc."

Recordemos que aún cuando lo derechos a la libertad física y a la libre locomoción, lo mismo que los derechos políticos, se encuentran restringidos en contra de las personas que se encuentran privadas de la libertad $^{10}$, los demás derechos fundamentales permanecen intactos a favor de la población carcelaria y por la situación de hacinamiento los mismos no han podido ser garantizados por parte del Estado ${ }^{11}$.

Ahora bien, a pesar de las órdenes impartidas por nuestro Tribunal Constitucional, hoy en día y transcurridos más de catorce años, el gobierno se encuentra en mora de dar cumplimiento a este deber constitucional. En la actualidad, más del 30\% de las personas privadas de la libertad, no han sido condenadas ${ }^{12}$. Esta cifra, compaginada con el índice de hacinamiento carcelario que en la actualidad supera el $51 \%{ }^{13}$ de la

${ }^{4}$ Fuente: Informe INPEC - Enero 31 de 2013. Capítulo "Población internos en Establecimiento de Reclusión y regionales".
${ }^{5}$ Fuente: Informe INPEC - Enero 31 de 2013. Capítulo "Población internos en Establecimiento de Reclusión y regionales"
${ }^{6}$ Paradigmático el caso desarrollado en la sentencia T-506/13, M.P. Nilson Pinilla Pinilla, en donde el accionante (privado de la
libertad en la Cárcel Nacional Modelo) y quien a su vez ostenta la calidad de ex policía, se encontraba en un patio común, sin
ninguna clase de aislamiento.
7 "Nadie será sometido a torturas ni a penas o tratos crueles, inhumanos o degradantes. En particular, nadie será sometido sin su libre consentimiento a experimentos médicos o científicos"

8 "1. Toda persona privada de libertad será tratada humanamente y con el respeto debido a la dignidad inherente al ser humano. 2. a) Los procesados estarán separados de los condenados, salvo en circunstancias excepcionales, y serán sometidos a un tra tamiento distinto, adecuado a su condición de personas no condenadas; b) Los menores procesados estarán separados de los adultos y deberán ser llevados ante los tribunales de justicia con la mayor celeridad posible para su enjuiciamiento. 3. El régimen penitenciario consistirá en un tratamiento cuya finalidad esencial será la reforma y la readaptación social de los penados. Los menores delincuentes estarán separados de los adultos y serán sometidos a un tratamiento adecuado a su edad y condición jurídica."

${ }^{9}$ Sentencia T-153/98

10 "Asimismo, derechos como los de la intimidad personal y familiar, reunión, asociación, libre desarrollo de la personalidad y libertad de expresión se encuentran restringidos, en razón misma de las condiciones que impone la privación de la libertad” Ibídem

${ }^{11}$ En el texto "The decent society", Margalit (1996) construye una filosofía moral con base en la siguiente premisa: una sociedad decente, o una sociedad civilizada, es aquella cuyas instituciones no humillan a las personas sujetas a su autoridad, y cuyos ciudadanos no se humillan unos a otros. Estableciendo que los mejores escenarios para analizar que tan decente es la sociedad de un Estado, son los hospitales y las cárceles.

12 http://www.elespectador.com/impreso/opinion/columna-288722-los-excesos-detencion-preventiva (Página de internet consultada por última vez el 9 de agosto de 2013).

${ }^{13}$ Fuente: Informe INPEC - Enero 31 de 2013. Capítulo "Población internos en Establecimiento de Reclusión y regionales" Disponible on line: http://relatorestematicos.uniandes.edu.co/index.php/es/relatorias/40/533-novedades.html (Página de internet consultada por última vez el 9 de agosto de 2013). Para el año 2008 este porcentaje era del 30.7 y para el 2010 aumentó a 41.7. Cfr. SITUACIÓN CARCELARIA EN COLOMBIA, $99^{\circ}$ período de sesiones, Ginebra, Suiza, Julio de 2010, INFORME vol.08, nº.03, Rio de Janeiro, 2015.pp. 1271-1305 1272 
población intramuros, es alarmante. En estas condiciones, la construcción de nuevos centros de reclusión ${ }^{14}$ no contribuye de manera significativa a esta problemática y se debe propender por la búsqueda de otras medidas que permitan siquiera matizar esta problemática, como el otorgamiento flexibilizado de libertades condicionales ${ }^{15}$ y los sistemas de vigilancia electrónica, cuyos requisitos legales imposibilitan la decisión favorable a los intereses de los internos.

Uno de estos requisitos era el pago de la multa, frente al cual, generalmente los internos carecen de recursos para sufragarla y como consecuencia, las solicitudes ante los Juzgados de Ejecución de Penas y Medidas de Seguridad tendientes a resultar beneficiados con alguno de estos sustitutos penales, no tenían vocación de prosperidad.

La Corte Constitucional a través de las sentencias C-185/11 y T-309/12 estableció que la exigencia del pago de la multa para efectos de conceder los sustitutos de la pena de prisión de: a) los sistemas de vigilancia electrónica y b) la libertad condicional, no era procedente frente al condenado insolvente, por resultar discriminatoria.

Nótese, por ejemplo, en el delito de tráfico, fabricación o porte de estupefacientes (artículo 376 del Código Penal Colombiano) por el cual se encuentra recluido el $13.5 \%$ de la población carcelaria ${ }^{16}$, cómo las penas de multa están comprendidas entre 2 y 50.000 S.M.L.M.V. ${ }^{17}$ (\$1 133.400 - 28.335'000.000 para el año 2012), dependiendo de la cantidad de estupefacientes sobre la cual se constituya el objeto material del delito. Estas sumas probablemente podrán ser sufragadas por los grandes narcotraficantes - para quienes se encuentra prohibido expresamente el otorgamiento de los sistemas de vigilancia electrónica y la libertad condicional-, pero no por los pequeños expendedores, quienes son utilizados como correos humanos (las denominadas "mulas") o por los portadores que sobrepasaron el límite establecido para la dosis personal. ¿No será que a estos últimos especialmente a los portadores (por encima del debate de antijuridicidad material)-, se les puede ofrecer otra alternativa de castigo que no implique la internación intramural brindando así una solución al hacinamiento

SOMBRA PRESENTADO AL CDH DE NACIONES UNIDAS, En respuesta al SEXTO INFORME DE COLOMBIA, Presentado por: Grupo de Derecho de Interés Público. Facultad de Derecho. Universidad de los Andes. Bogotá. Colombia. The Carlos A. Costa Immigration and Human Rights Clinic at Florida International University College of Law. United States, p. 41. Curiosamente las estadísticas del Ministerio de Justicia no coinciden con estas cifras. La sobrepoblación para el año 2008, allí indicada, es de 27.75\%, para el 2009: 38.80\%, 2010: 24.42\%, 2011:32.80\% y 2012: 50.39\% (Fuente: 12 pasos para hacerle frente a la crisis del sistema penitenciario y carcelario, Ministerio de Justicia, Bogotá, Enero de 2013).

${ }^{14}$ En el mes de marzo del año 2011 se inauguró el pabellón "Eron” de la Cárcel "La Picota" cuya imponencia resalta dentro del deprimido sector de la localidad de Usme (Bogotá - Colombia). No obstante lo anterior, las principales críticas de esta estructura corresponden a la temperatura y la carencia de luz. Ver: http://www.diariolibre.com/latinoamerica/2012/09/08/i351182_lasprisiones-colombia-hay-cama-patanta-gente.html, circunstancias que sugieren la otrora calificación del condenado como un monstruo "Tema frecuente en la época [el autor se refiere al siglo XVIII]: un criminal, en la medida misma de su monstruosidad, debe ser privado de la luz: no ver ni ser visto" (Foucault 1983, p. 204); claro que en el panóptico él es visto, pero no ve.

15 "Durante largo tiempo se concedió la libertad condicional por razones de economía o para atenuar la enorme sobrepoblación de las prisiones” (Cuello, 1958, p. 537)

${ }^{16}$ Informe INPEC 1993-2012. Capítulo "Modalidad delictiva y población de internos" (Tabla 18)

${ }^{17}$ Estas siglas corresponden al monto del salario mínimo legal mensual vigente para Colombia vol.08, nº. 03, Rio de Janeiro, 2015.pp. 1271-1305 
carcelario? Incluso, ¿ No resulta más eficiente para el Estado la concesión de estos sustitutos penales que el precio equivalente a la privación de la libertad? ${ }^{18}$

A pesar de obtenerse una maximización de recursos a través del otorgamiento de sistemas de vigilancia electrónica (Hernández, 2012), solo 3.671 personas a nivel nacional se encuentran beneficiados de los mismos ${ }^{19}$ monto que no supera el 3.65\% de la población de internos (100.451) y en una proporción significativa, la negativa para su otorgamiento, obedecía al no pago de la multa. Lo mismo ocurría con la libertad condicional donde el costo de transacción es mucho más reducido, sin embargo las solicitudes al respecto, eran despachadas desfavorablemente, de manera preponderante.

Corolario de lo anterior, se ofrece a los lectores el resultado de una investigación referente a la aplicación que los Juzgados de Ejecución de Penas y Medidas de Seguridad de Bogotá20 ${ }^{20}$ hacían en el año 2012, del precedente judicial con base en el cual, el condenado insolvente no estaba obligado a sufragar el pago de la multa, confrontándola con la modificación que al respecto introdujo el legislador colombiano del año 2014. En los acápites posteriores se explicará en qué consisten los sustitutos penales de la libertad condicional y los sistemas de vigilancia electrónica dentro de nuestro contexto, abordando con posterioridad el análisis sobre el criterio de la Corte Constitucional sobre estos tópicos y la exigencia de la multa para su concesión.

En lo metodológico se aplicó el método comparativo con el fin de establecer la variación en el sentido de las decisiones de los J.E.P.M.S.BTA. durante el año 2012 y la influencia de las sentencias C-185/11 y T-309/12 en las providencias relacionadas con el otorgamiento de libertades condicionales y sistemas de vigilancia electrónica. También dentro de los métodos cualitativos se recurrió a un enfoque socio-jurídico e interdisciplinario, que fue compaginado con el método cuantitativo, a través del cual se establecieron la cantidad de solicitudes radicadas ante los Juzgados $1^{\circ}$ E.P.M.S.BTA. y $9^{\circ}, 10^{\circ}$ y $11^{\circ}$ de E.P.M.S.BTA. (Descongestión), así como el número que fueron despachadas favorable y desfavorablemente, constituyéndose estas como mi fuente primaria ${ }^{21}$.

En este punto una pregunta inevitable sería: ¿Por qué se optó por el análisis de estos Juzgados de manera exclusiva? La respuesta tiene el siguiente contexto: dentro de mi práctica profesional independiente y la actividad pedagógica en la que he participado con el Grupo de Derecho de Interés Público (G-DIP) y la Relatoría de

\footnotetext{
${ }^{18}$ El gasto anual de operación por interno es de \$1 1 093.445. Informe INPEC 1993-2012. Capítulo "Costo por interno" (Tabla 31).

${ }^{19}$ Informe INPEC 1993-2012. Capítulo "Población de internos con vigilancia electrónica (De acuerdo a la ejecución de la medida y con información a abril de 2012)" (Tabla 23)

${ }^{20}$ En lo sucesivo se utilizarán las siguientes siglas J. (Juzgado), E. (Ejecución), P. (Penas), M. (Medidas), S. (Seguridad) y BTA. (Bogotá). $\sum=$ J.E.P.M.S.BTA.

21 "[... toda investigación histórica comienza con la selección de un tema y la localización de unas fuentes pertinentes" (Silva, 2003, p. 28). "[... ] los historiadores suelen dividir las fuentes de su conocimiento en fuentes primarias por una parte y fuentes secundarias, por la otra. Las primarias son aquellas que están expresadas en documentos y constituyen precisamente el material de los archivos públicos y otros archivos históricos, constituidos por documentos que produjeron directamente los actores de la historia." (Jaramillo Uribe, 1993, p. 35, citado por Barreto, 2011, p. 24)
} 
Prisiones de la Universidad de los Andes, he observado cierto hermetismo para acceder a la información que reposa en los archivos de los J.E.P.M.S. No obstante lo anterior y frente a la motivación por el reto de acceder a los mismos, se logró contactar a la Juez $1^{\circ}$.E.P.M.S.BTA.22 que permitió el acceso incondicional al archivo de su despacho.

Pero un juzgado no sería suficiente en términos cuantitativos para ponderar la situación objeto de investigación ${ }^{23}$. Por sugerencia del profesor Libardo Ariza opté por superar un $10 \%$ del total de J.E.P.M.S.BTA. ${ }^{24} \mathrm{y}$ el acuerdo PSAA12-9635 del 2 de agosto de 2012, expedido por la Sala Administrativa del Consejo Superior de la Judicatura, fue un pretexto perfecto. A través de este acuerdo, se adoptan como medidas de descongestión para los Juzgados de Ejecución de Penas y Medidas de Seguridad de Bogotá, la creación de 3 Juzgados que conocerían - a partir del 8 de agosto de 2012 -, de manera exclusiva, las solicitudes de libertad represadas, decidiendo analizar las providencias proferidas por estos despachos desde su creación hasta el mes de noviembre de 2012. Comoquiera que estos juzgados monopolizaron dichas solicitudes, logré analizar el universo de investigación.

Uno de los principales obstáculos dentro de esta labor de investigación fue el paro judicial del año $2012^{25}$ que me impidió el acceso a mi fuente primaria por más de 30 días, sin embargo al final, gracias -nuevamente- a la colaboración de la Juez $1^{\circ}$ E.P.M.S.BTA, se logró el análisis de las providencias que reposaban en el archivo de los Juzgados seleccionados ${ }^{26}$, que ostentan para efectos de esta investigación, la calidad de "actores de la historia".

\section{DE LOS MECANISMOS SUSTITUTIVOS DE LA PENA DE PRISIÓN}

Los mecanismos sustitutivos de la pena de prisión son dispositivos que permiten cambiar o mutar la internación en establecimiento penitenciario, por la alternativa de no purgar la pena (suspensión condicional de la ejecución de la pena), purgarla en el lugar de residencia (prisión domiciliaria y sistemas de vigilancia electrónica) o purgar un tiempo determinado en prisión y poder salir de ella en un lapso inferior a la pena definitiva impuesta (libertad condicional). Estos mecanismos son analizados en la fase de conocimiento (suspensión condicional de la ejecución de la pena y prisión domiciliaria) y durante la fase de ejecución del proceso penal27.

\footnotetext{
${ }^{22}$ Debo agradecer a la Juez $1^{\circ}$ de E.P.M.S.BTA. (Dra. Raquel Aya Montero) quien permitió el acceso a las providencias emitidas por su despacho, relacionadas con el tema de mi investigación, así como el contacto con los jueces $9^{\circ}, 10^{\circ}$ y $11^{\circ}$ de E.P.M.S.BTA. (Descongestión)

${ }^{23}$ Observaciones realizadas por los profesores Antonio Barreto y Libardo Ariza (Universidad de los Andes).

${ }^{24}$ Para la fecha existían 30 J.E.P.M.S.BTA (19 permanentes/radicados, 8 provisionales y 3 de descongestión). Se estudiaron los Juzgados de este circuito judicial por la facilidad de traslado a los mismos, en la medida que mi sede académica corresponde a este Distrito Capital.

${ }^{25}$ Los trabajadores de la Rama Judicial (Colombia) adelantaron un cese de actividades con el objetivo de obtener una nivelación salarial. Sobre el tema se puede consultar: http://www.elespectador.com/tags/paro-judicial

${ }^{26}$ A pesar del paro judicial, estos juzgados continuaron laborando, resolviendo en especial libertades y acciones de habeas corpus.

${ }^{27}$ La literatura sobre el tema es escaza. Los manuales de procedimiento penal colombiano tradicionales, no se ocupan de esta fase de ejecución de la pena, Cfr. Bernal y Montealegre (1985, 1990, 2002 y 2004) y Martínez Rave (1994, 1997, 2002 y 2006), con excepción del texto de Espitia (2010, p. 461-471), donde sumariamente se expone este tópico, ratificando así lo expresado por vol.08, nº. 03, Rio de Janeiro, 2015.pp. 1271-1305 1275
} 
Sea oportuno manifestar que la concesión de alguno de estos mecanismos no elimina la pena de prisión, ya que esta permanece vigente ${ }^{28} \mathrm{y}$ es por esto que el condenado se somete a un periodo de prueba $\mathrm{y}$ al cumplimiento de determinadas obligaciones.

Para los efectos de esta investigación, tal como se anticipaba con anterioridad, sólo se analizó la libertad condicional y los sistemas de vigilancia electrónica como sustitutivos de la prisión y de manera especial, el requisito de la multa. Se procede entonces a examinar las características de cada uno de estos mecanismos, citando su consagración legal, para facilitar su entendimiento por parte de los lectores legos en materia penal.

\section{Los sistemas de vigilancia electrónica}

El legislador del año 2007, a través de la ley 1142 (artículo 50) incluyó dentro de la parte general del Código Penal, la otrora consagración establecida en el artículo 29 B de la ley 65 de 1993 (Código Penitenciario y Carcelario) obsoleta - sobre la posibilidad de sustituir la pena de prisión por sistemas de vigilancia electrónica.

Establecía así el artículo 38A del Código Penal (modificado por el artículo $3^{\circ}$ la ley 1453 de 2011) que:

El Juez de Ejecución de Penas y Medidas de Seguridad podrá ordenar la utilización de sistemas de vigilancia electrónica durante la ejecución de la pena, como sustitutivos de la prisión, siempre que concurran los siguientes presupuestos:

1. Que la pena impuesta en la sentencia no supere los ocho (8) años de prisión.

2. Que la pena impuesta no sea por delitos de genocidio, contra el Derecho Internacional Humanitario, desaparición forzada, secuestro extorsivo, tortura, desplazamiento forzado, tráfico de menores de edad, uso de menores de edad para la comisión de delitos, tráfico de migrantes, trata de personas, delitos contra la

Foucault en el sentido que "El castigo tenderá, pues, a convertirse en la parte más oculta del proceso penal” (1983, p. 17). En sentido similar al desarrollado por Espitia sobre la ejecución de la pena, se encuentra a Urazán (2002). En los textos de FierroMendez (2012, p. 1722) y Urrutia y Cuesta (2008, p. 1145) se desarrolla el tema, sin embargo estos libros no están catalogados dentro de ese ámbito "tradicional". Mauricio Rubio (1996) al hablar de la cronología del proceso judicial refiere que "la última etapa la constituye la intervención del aparato judicial para solucionar mediante sentencia el litigio”. ¿Qué pasa entonces con la ejecución de la pena? ¿No hace parte del proceso penal? Roxin (2000) dentro del capítulo 11 hace algunos comentarios sobre la ejecución de la pena pero no desarrolla el tema. Ferrajoli (1997, p.p. 727-728) anota algunas referencias sobre las penas sustitutivas y López Barja, a pesar de su fervoroso discurso sobre la importancia del Juez “de vigilancia penitenciaria” (2012, p.p. 2323-2324) se limita a analizar los recursos contra las decisiones de estos jueces. Por otra parte, Jiménez (1949, p. 433) consagra un capítulo sobre la ejecución de la pena que no hace relación a los mecanismos sustitutivos de la pena.

En el ámbito sustantivo nacional, la situación es diferente y aunque no se ocupan de la fase de ejecución -propia del procedimiento penal- hacen relación a la libertad condicional en su calidad de subrogado penal. Cfr. en este sentido Arboleda y Ruiz (202, p. 323), Reyes (1974, p. 364) y Velázquez (2007, p. 614 y 2009, p. 1167). Este último dentro del capítulo decimoctavo, aparte C, habla de los mecanismos sustitutivos de la pena de prisión y desarrolla la libertad condicional. Por la doctrina foránea baste citar a Zaffaroni (1983) que en el aparte IV dentro del capítulo XL "La libertad condicional como última etapa de la ejecución de la pena privativa de la libertad" desarrolla el tema.

No obstante lo anterior, los sistemas de vigilancia electrónica como sustitutivos de la pena de prisión, es un tema poco desarrollado en los textos penales, encontrando sólo en Urrutia y Cuesta (2009, p. 111-112) una pobre descripción exegética (que algunos calificarían como "auténtica") sobre el tema.

${ }^{28}$ En el mismo sentido Ruiz (1997, p. 227) 
libertad, integridad y formación sexuales, extorsión, concierto para delinquir agravado, lavado de activos, terrorismo, usurpación y abuso de funciones públicas con fines terroristas, financiación del terrorismo y de actividades de delincuencia organizada, administración de recursos con actividades terroristas y de delincuencia organizada, financiación del terrorismo y administración de recursos relacionados con actividades terroristas, delitos relacionados con el tráfico de estupefacientes, fabricación, tráfico y porte de armas y municiones de uso privativo de las fuerzas armadas y fabricación, tráfico y porte de armas de fuego, municiones o explosivos y delitos contra la administración pública, salvo delitos culposos.

3. Que la persona no haya sido condenada por delito doloso o preterintencional dentro de los cinco (5) años anteriores.

4. Que el desempeño personal, laboral, familiar o social del condenado permita al Juez deducir seria, fundada $y$ motivadamente que no colocará en peligro a la comunidad y que no evadirá el cumplimiento de la pena.

5. Que se realice o asegure el pago de la multa mediante garantía personal, prendaria, bancaria o mediante acuerdo, salvo cuando se demuestre que está en incapacidad material de hacerlo teniendo en cuenta sus recursos económicos y obligaciones familiares.

6. Que sean reparados los daños ocasionados con el delito dentro del término que fije el Juez o se asegure su pago mediante garantía personal, prendaria, bancaria o mediante acuerdo, salvo cuando se demuestre que está en incapacidad material de hacerlo teniendo en cuenta sus recursos económicos y obligaciones familiares.

7. Que se garantice mediante caución el cumplimiento de las siguientes obligaciones, las cuales deberán constar en un acta de compromiso:

a. Observar buena conducta;

b. No incurrir en delito o contravención mientras dure la ejecución de la pena;

c. Cumplir con las restricciones a la libertad de locomoción que implique la medida;

d. Comparecer ante quien vigile el cumplimiento de la ejecución de la pena cuando fuere requerido para ello.

El incumplimiento de las obligaciones impuestas en el acta de compromiso dará lugar a la revocatoria de la medida sustitutiva por parte del Juez de ejecución de penas y medidas de seguridad.

8. Que el condenado no se haya beneficiado, en una anterior oportunidad, de la medida sustitutiva de pena privativa de la libertad.

Parágrafo $1^{\circ}$. El juez al momento de ordenar la sustitución deberá tener en cuenta el núcleo familiar de la persona y el lugar de residencia.

Parágrafo $2^{\circ}$. La persona sometida a vigilancia electrónica podrá solicitar la redención de pena por trabajo o educación ante el Juez de ejecución de penas y medidas de seguridad, de acuerdo a lo señalado en el Código Penitenciario y Carcelario.

Parágrafo $3^{\circ}$. Quienes se encuentren en detención preventiva en establecimiento carcelario bajo el régimen de la Ley 600 de 2000 podrán ser destinatarios de los sistemas de vigilancia electrónica, previo cumplimiento de los presupuestos establecidos en el artículo 314 de la Ley 906 de 2004. 
Parágrafo $4^{\circ}$. El Instituto Nacional Penitenciario y Carcelario, suministrará la información de las personas cobijadas con esta medida a la Policía Nacional, mediante el sistema de información que se acuerde entre estas entidades, dentro de los seis meses siguientes a la expedición de esta ley.

Este artículo será reglamentado por el Gobierno Nacional para garantizar las apropiaciones del gasto que se requieran para la implementación del citado sistema de vigilancia electrónica dentro de los 60 días siguientes a su sanción.

De la lectura de la norma jurídica (artículo 38A del Código Penal), fácil resulta colegir que el requisito objetivo para su otorgamiento consiste en que la pena impuesta no supere los 8 años de prisión. Ahora bien, a través de la Ley 1453 de 2011 se introdujeron dentro del listado de delitos que imposibilitan la concesión de este mecanismo el tráfico de menores de edad y el uso de menores de edad para la comisión de delitos, conductas protegidas como mecanismo de seguridad ciudadana. Igualmente el terrorismo y la usurpación y abuso de funciones públicas con fines terroristas, por las implicaciones del nuevo orden mundial en materia de seguridad desde el 9-11. La fabricación, tráfico y porte de armas de fuego o municiones - sean o no de uso privativo de las fuerzas armadas - considerando que a través de este delito se propicia la comisión de otros y por último, los delitos contra la administración pública - exceptuando la modalidad culposa - con ocasión de los recientes escándalos en la contratación pública y la concesión de subsidios, conductas estas últimas que no resultan novedosas si se analizan en retrospectiva casos como Dragacol, Foncolpuertos y Cajanal, confrontados con el actual escándalo de AIS.

También se incluyó la prohibición de conceder este mecanismo a quienes hayan resultado beneficiados con anterioridad del mismo y se incorporó la tesis jurisprudencial sentada por la Corte Constitucional a través de la sentencia C-185/11 referente a la incapacidad de pago de la multa.

El Sistema funcionaba a través de la instalación de un dispositivo electrónico (brazalete o una tobillera) en el cuerpo del condenado o sindicado - con su consentimiento-, el cual lleva incorporada una unidad transmisora, generando la ubicación del sujeto e indicando si ha llegado a zonas de exclusión.

El Decreto 177 de 2008, modificado por el Decreto 1316 de 2009 (artículos $3^{\circ}$ y 4), consagró las siguientes modalidades para la concesión de este beneficio:

1. "Seguimiento Pasivo RF. Es el sistema de vigilancia electrónica ordenado por el juez o como medida de control adoptada por el Instituto Nacional Penitenciario y Carcelario, según sea el caso, a través del cual se instala un dispositivo consistente en un brazalete o una tobillera en el cuerpo del condenado, sindicado, imputado o acusado, según fuere el caso, el cual trasmite a una unidad receptora, la que a su vez se encuentra conectada a una línea telefónica convencional"

2. "Seguimiento activo-GPS. Es el sistema de vigilancia electrónica a través del cual se instala un dispositivo consistente en un brazalete o tobillera en el cuerpo del sindicado, imputado o acusado, según fuere el caso el cual llevará incorporada una unidad GPS (Sistema 
de posicionamiento global), la cual transmitirá la ubicación del beneficiario, indicando si ha llegado a zonas de exclusión. Cuando el beneficiario del dispositivo llegue al lugar establecido para el cumplimiento de la medida de aseguramiento, la información que así lo indique será transmitida al centro de monitoreo, sin que durante el transcurso del día se haya perdido la transmisión inherente al sistema de vigilancia electrónica. Dicha comunicación se llevará a cabo vía telefónica o móvil."

3. "Reconocimiento de Voz. Es el sistema de vigilancia electrónica sustitutivo de la pena de prisión o de la detención preventiva, a través del cual se lleva a cabo una llamada al lugar de residencia del condenado o sindicado, y autentica su identidad comparando su voz contra una impresión de voz previa tomada durante el proceso de registro."

Como se verá en el capítulo correspondiente a la aplicación del precedente en los Juzgados de Ejecución de Penas y Medidas de Seguridad de Bogotá y tal como se anunciara en la introducción de este texto, los J.E.P.M.S. eran renuentes al otorgamiento de este beneficio, incluso cuando se había cancelado el valor de la multa, especialmente por las prohibiciones expresas contenidas en el artículo 68 A del Código Penal, relacionadas, por ejemplo, con la comisión de delitos contra la administración pública ${ }^{29}$, de conformidad con lo normado en la ley 1474 de 2011 (Estatuto anticorrupción), aunque el trasfondo de estas decisiones, así como las relacionadas con la libertad condicional, corresponden a criterios de independencia judicial que serán analizados más adelante.

Por último es preciso advertir que este mecanismo fue derogado por la Ley 1709 (artículo 107) y solo opera como acompañante de la prisión domiciliaria en la actualidad (artículo 25).

\section{La libertad condicional}

La libertad condicional -libertad bajo palabra en el sistema anglosajón (parole) ${ }^{30}$ - es la liberación del preso una vez haya cumplido un determinado tiempo (requisito objetivo ${ }^{31}$ ) recluido intramuros y tras haber mostrado una conducta adecuada en el establecimiento de reclusión (requisito subjetivo), quedando el condenado sujeto a un período de prueba posterior ${ }^{32}$. La regulación actual consagra un requisito objetivo que corresponde a las tres quintas partes $(3 / 5)$ de la pena impuesta ${ }^{33}$. Por su parte el requisito subjetivo se demuestra a

\footnotetext{
${ }^{29}$ Cfr. COLOMBIA, Rama Judicial del Poder Público, Corte Suprema de Justicia, Sala de Casación Penal, providencia del 22 de julio de 2011, proceso 36926, M.P. Alfredo Gómez Quintero

${ }^{30}$ Para un análisis sobre la historia de este mecanismo remitimos al lector a las obras de Alderete (2007, p.p. 1-4), Arboleda y Ruíz (2002, p.p. 324-326), Cuello (1958, p.p. 535-536), Daien (1947, p.p. 40-49), Velásquez (2009, p. 1168) y Zaffaroni (1983, p.p. 175-178).

${ }^{31}$ Denominado por Alderete (2007, p. 75) "requisito temporal"

${ }^{32}$ Recurriendo a Foucault (1983, p.p. 199-230 y 1998, p.p. 98-100, 117, 120-137) y en desarrollo de la idea original de Bentham, el individuo saldría del Panóptico penitenciario para entrar en el panóptico social.

${ }^{33}$ Con anterioridad a las Ley 1709 de 2014, para los procesos regidos por el sistema de enjuiciamiento penal con tendencia acusatoria (Ley 906 de 2004) se exigía un requisito objetivo correspondiente a las dos terceras (2/3) partes de la pena, diferenciándose con los procesos regidos por el sistema de enjuiciamiento penal con tendencia inquisitiva (Ley 600 de 2000), quantum que quedó unificado en la actualidad.
} 
través de la resolución favorable emitida por el director del establecimiento penitenciario encargado de la custodia del sentenciado, en donde conste su buen comportamiento intramuros.

De antaño la doctrina ha considerado que la libertad condicional cumple una función moral y otra social. A través de la primera se premia al condenado (Cuello 1958, 537); mediante la segunda se incentiva a sus compañeros para seguir su ejemplo, optimizando así la función de rehabilitación (Pannain 1950, 728, citado por Reyes 1974,364). Sin embargo, como veremos a continuación, la consagración legal actual de este mecanismo no se compagina con esta filosofía, incluyendo otros requisitos que restringen su aplicación.

El artículo 64 del Código Penal, modificado por el artículo 30 de la Ley 1709 de 2014, establece que:

El juez, previa valoración de la conducta punible, concederá la libertad condicional a la persona condenada a pena privativa de la libertad cuando haya cumplido con los siguientes requisitos:

1. Que la persona haya cumplido las tres quintas (3/5) partes de la pena.

2. Que su adecuado desempeño y comportamiento durante el tratamiento penitenciario en el centro de reclusión permita suponer fundadamente que no existe necesidad de continuar la ejecución de la pena.

3. Que demuestre arraigo familiar y social.

Corresponde al juez competente para conceder la libertad condicional establecer, con todos los elementos de prueba allegados a la actuación, la existencia o inexistencia del arraigo.

En todo caso su concesión estará supeditada a la reparación a la víctima o al aseguramiento del pago de la indemnización mediante garantía personal, real, bancaria o acuerdo de pago, salvo que se demuestre insolvencia del condenado.

El tiempo que falte para el cumplimiento de la pena se tendrá como periodo de prueba. Cuando este sea inferior a tres años, el juez podrá aumentarlo hasta en otro tanto igual, de considerarlo necesario.

Encontramos entonces, como requisito adicional a los tradicionalmente consagrados para el otorgamiento de este beneficio: la valoración de la conducta punible. Enhorabuena, la Ley 1709 eliminó la exigencia del pago de la multa y los perjuicios como requisito para acceder a este subrogado ${ }^{34}$ e igualmente suprimió la exclusión de los delitos consagrados en el artículo $68 \mathrm{~A}^{35}$ del Código Penal ${ }^{36}$, que otrora imposibilitaban en gran medida, acceder a este subrogado penal.

\footnotetext{
${ }^{34}$ Ver Gacetas del Congreso Colombiano Nos. 298 (20-05-13), 668 (02-09-13), 941 (20-11-13) en la exposición relacionada con el "régimen de libertades".

${ }^{35}$ El parágrafo $1^{\circ}$ del artículo 68A del Código Penal consagra que: "Lo dispuesto en el presente artículo no se aplicará a la libertad condicional contemplada en el artículo 64 de este Código, ni tampoco para lo dispuesto en el artículo 38G del presente Código." (Resaltado fuera del texto).

${ }^{36}$ Tal y como pasaba con anterioridad a la reforma de la ley 1709 de 2014, el artículo 14 del Código Penal argentino excluye algunos delitos del beneficio de libertad condicional: (i) homicidio criminis causa, (ii) abusos sexuales seguidos de muerte, privación ilegitima de la libertad agravada por haber causado intencionalmente la muerte de la víctima, (iii) homicidio con motivo o con ocasión de robo y (iv) secuestro extorsivo seguido de la muerte intencional de la víctima, las cuales tiene pena de prisión perpetua, con excepción de la conducta contenida dentro del literal (iii).
} 
En cuanto a la valoración de la conducta punible, la crítica fundamental - sobre la cual no ahondaré por no hacer parte del objeto específico de esta investigación -, está relacionada con la regresión jurídica hacia los criterios de derecho penal de autor ${ }^{37}$ aunado a que esta situación ya fue analizada en pretérita oportunidad por el juez de conocimiento para tasar la pena y al evaluar, ora por petición de parte dentro del traslado del artículo 447 del Código de Procedimiento Penal, ya de oficio, la procedencia de la suspensión condicional de la ejecución de la pena (artículo 63 del Código Penal).

Con anterioridad a la reforma establecida en la Ley 890 de 2004 - que adoptó ciertos criterios tendientes a poner en funcionamiento un sistema de enjuiciamiento penal de corte acusatorio -, solo se exigía el buen comportamiento del condenado, presumiendo que a través de este, se certificaba su readaptación social (FierroMendez, 1998, p. 223), encontrando en la actual legislación un retroceso jurídico que afecta directamente el sistema carcelario y por ende los índices de hacinamiento.

\section{DE LA PERSPECTIVA CONSTITUCIONAL FRENTE AL PAGO DE LA MULTA}

La multa es una sanción pecuniaria que hace parte del ius puniendi del Estado y que se impone de manera única principal o acompañante de la pena de prisión, como consecuencia del comportamiento disvalioso, determinado a través de una sentencia condenatoria ${ }^{38}$. Sobre el cambio de la multa como pena principal, oportuna la cita Rusche y Kirchheimer (1984, p.p. 18-19) directamente relacionada al objeto de estudio (discriminación económica): "De este modo, quienes poseían dinero suficiente para pagar, podían comprar la exención de las penas; aunque los condenados indigentes (que constituían la gran mayoría en esos tiempo difíciles) estaban incapacitados para salvarse del tratamiento riguroso al que eran sometidos" anticipando así un criterio de discriminación y de eventual privación de derechos como consecuencia de la imposibilidad económica.

En torno a la exigibilidad de la multa para acceder a los mecanismos sustitutivos de la pena de prisión, la Corte Constitucional mediante sentencias C-194, C-665, C-783 y C-823 de 2005, había mantenido la misma línea jurisprudencial en cuanto: (i) el carácter de multa es sancionatorio y se origina en la configuración de una conducta penal, luego no responde a criterios transaccionales, obligacionales, ni contractuales, por lo cual su exigencia debe entenderse en el ámbito del cumplimiento de una pena, y no con la vocación de discriminar a personas de bajos recursos económicos, y (ii) la regulación legal de la multa en materia penal brinda alternativas para el cumplimiento de su pago, que pretenden atender la realidad social y económica de quienes se encuentran

\footnotetext{
37 “[... ] lo que es una indeseable exigencia propia de un derecho penal de autor que contraría la Constitución (no obstante, la sentencia C-194 de 2005, afirma lo contrario, aunque entiende que esa evaluación debe hacerse en los mismos términos en que lo haya hecho el juzgador al emitir la sentencia de condena) [... . Los límites al ejercicio de la potestad punitiva del Estado, pues, son descaradamente burlados". (Velásquez, 2007, p. 615)

${ }^{38}$ En el mismo sentido Cfr. sentencias C-390/02, C-194/05 y C-185/11
} 
condenados penalmente, con lo cual no se encuentran discriminados los condenados de bajos recursos económicos.

Mediante sentencia C-185 de $2011^{39}$ se estableció que la exigencia del pago de la multa para resultar beneficiado del sistema sustitutivo de la vigilancia electrónica resultaba discriminatorio, con base en los siguientes argumentos:

1. La pena privativa de la libertad en una cárcel es el castigo más gravoso en materia penal, por lo cual las alternativas de su cumplimiento fuera del establecimiento carcelario cobran gran importancia en el contexto de la garantía de una gran variedad de derechos que se restringen por el hecho de estar en una cárcel.

2. Por lo anterior la consagración legal de la posibilidad de salir de la cárcel y cumplir la pena privativa de libertad fuera de ella, debe brindarse en igualdad de condiciones, y no puede depender de exigencias ajenas a las que interesan de manera especial a la legislación penal.

3. Por ello, cuando el acceso a la mencionada posibilidad depende de los medios económicos del condenado, las desigualdades de hecho se convierten en desigualdades jurídicas, y sin justificación constitucional alguna sólo quienes tienen recursos económicos ostentan realmente la alternativa.

4. Las mencionadas desigualdades, no resultan matizadas en el caso concreto por los criterios desarrollados por la Corte en los casos de la exigencia de la multa para acceder a la libertad condicional y a la suspensión condicional de la ejecución de la pena.

5. Además de que la exigencia de la multa en el caso de la vigilancia electrónica no encuentra sustento alguno en la consecución de un fin constitucionalmente relevante, como para afirmar que su exigencia busca garantizar un valor constitucional superior al contenido en el principio de igualdad.

El anterior discernimiento fue ratificado por el legislador del año 2011 a través de la Ley 1453 -insistoque en los numerales 5 y 6 del artículo 38A del Código Penal consagró la imposibilidad de pago de la multa y/o la indemnización de perjuicios, como excepción para resultar beneficiado del sustituto. Esta postura se asimila a la tesis sobre la discriminación por situaciones de pobreza respecto a la sustitución de la prisión por multa, sostenida por la Suprema Corte de los Estados Unidos en los casos Tate Vs. Short, 401 U.S. 395 (1971) y Williams Vs. Illinois, 399, U.S. $235(1970)^{40}$.

Siguiendo con este análisis comparado, en el artículo 13 Código Penal argentino se consagra la misma exigencia sin embargo su jurisprudencia es más restrictiva que la nuestra: en caso de que el condenado no tenga

\footnotetext{
${ }^{39}$ M.P. Humberto Antonio Sierra Porto. En esta providencia se declaró la exequibilidad condicionada del numeral $4^{\circ}$ del artículo 50 de la Ley 1142 de 2007 (que adiciona el artículo 38A del Código Penal), en el entendido que en caso de demostrarse ante el Juez de Ejecución de Penas y Medidas de Seguridad la insolvencia actual del condenado, el no pago previo de la multa no impedirá la concesión del subrogado de vigilancia electrónica.

${ }^{40}$ En contra de esta posición ver Posner (1998, p. 218)
} 
recursos, la multa se convierte en días de prisión, acorde con lo establecido en el artículo 21 del mismo Código (Alderete, 2007, p. 148)

Por su parte en sentencia T-309/12 $2^{41}$ se reiteró el precedente consagrado en la sentencia C-185/11 haciendo extensiva su interpretación al mecanismo de la libertad condicional ${ }^{42}$. Con anterioridad a este pronunciamiento se hacía exigible el pago de la multa ${ }^{43}$, argumentando que la sentencia C-185/11 solo era aplicable para los sistemas de vigilancia electrónica e incluso actualmente, algunos funcionarios judiciales indagados informalmente sobre la fuerza vinculante de esta sentencia, le otorgaron poca importancia atendiendo a que es una sentencia $\mathrm{T}$ - (de tutela) y no una C-(de constitucionalidad $)^{44}$.

$\mathrm{Al}$ respecto es importante recordar que en materia de precedente judicial, el artículo 230 Constitucional estipula que los jueces solo están sometidos al imperio de la ley para efectos de adoptar sus decisiones y clasifica como criterio auxiliar de la actividad judicial, entre otros, a la jurisprudencia. A pesar de lo anterior, la Corte Constitucional ${ }^{45}$ dejó relegado a este campo axiológico "secundario" los obiter dicta - afirmaciones dichas de paso- de cada decisión; no así los ratione decidendi - fundamentos jurídicos suficientes- que resultan vinculantes yobligatorios.

Dentro de las providencias analizadas en desarrollo de esta investigación se observará como algunos J.E.P.M.S. - para el año 2012 -, seguían el precedente sentado en la sentencia C-185/11 y lo hacían extensivo a la libertad condicional - incluso sin citar la sentencia T-309/12 -, así como la negativa de otros Despachos de aplicar esta posición jurisprudencial.

\section{Aplicación del precedente en los Juzgados de Ejecución de Penas y Medidas de Seguridad de Bogotá}

Dentro de este capítulo se ofrecerán al lector los resultados del trabajo de campo realizado en el año 2012 dentro de los archivos de los J.E.P.M.S.BTA. seleccionados, superando el análisis de 1000 providencias, pero descartando aquellas relacionadas con libertades por pena cumplida, prescripción, prisión domiciliaria y limitando el estudio a aquellas atinentes a la libertad condicional y los sistemas de vigilancia electrónica como sustitutivos de la pena de prisión.

\footnotetext{
${ }^{41}$ M.P. Jorge Iván Palacio Palacio

42 “(...) las aclaraciones que hace la C-185 de 2011, el análisis contenido en dicho fallo introduce nuevos criterios de carácter constitucional que deben ser tenidos en cuenta por los jueces de ejecución de penas y medidas de aseguramiento al momento de decidir si deben otorgan o no el beneficio de libertad condicional cuando la persona que lo solicita no haya pagado la multa y manifieste que carece de recursos económicos para hacerlo."

${ }^{43}$ Cfr. Ramírez (2005, p. 321)

${ }^{44}$ Otros reconocieron no tener conocimiento de la existencia de esta providencia

${ }^{45}$ Cfr. Sentencia C-836/01, M.P. Rodrigo Escobar Gil
} 
El orden que se seguirá al interior de esta sección (numerales 1., 2., 3. y 4.) consistirá en relacionar las providencias que conceden la libertad condicional, aquellas que la niegan, las que conceden los sistemas de vigilancia electrónica y culminar con las que los niegan, haciendo un análisis de estos resultados. Para esto se subdividirán los hallazgos encontrados en los 4 despachos judiciales explorados.

\section{Archivo:J. $1^{\circ}$ de E.P.M.S BTA ${ }^{46}$}

La Juez $1^{\circ}$ de E.P.M.S BTA. consideraba que tras introducir la Ley 890 de 2004 la exigencia del pago de la multa y los perjuicios para la concesión de los sustitutos penales, se limitó la posibilidad, que en vigencia del antiguo sistema de enjuiciamiento penal, hacía más fácil su concesión ${ }^{47}$. Pero lo más preocupante es la falta de independencia judicial para la concesión de los mismos - aspecto en el cual confluyen todos los funcionarios entrevistados ${ }^{48}$ - quienes temen a la "avalancha" de investigaciones disciplinarias por parte del Consejo Superior de la Judicatura, que presume la mala fe de los funcionarios ${ }^{49}$. Por esto prefieren abstenerse de otorgar mecanismos sustitutivos de la pena de prisión, ahorrándose los costos de transacción ${ }^{50}$ de un eventual proceso disciplinario en su contra ${ }^{51}$.

Veamos los resultados obtenidos en este despacho ${ }^{52}$ :

\section{Concede Libertad Condicional}

Se encontraron 29 providencias de las cuales 9 habían sido negadas inicialmente por no acreditar el pago de la caución y que tras su constitución, son otorgadas y una por prescripción de la sanción penal. Las demás se relacionan a continuación, indicando el motivo de la decisión:

\footnotetext{
${ }^{46}$ Juez: Raquel Aya Montero

${ }^{47}$ Entrevista realizada el 7 de septiembre de 2012 en el J.1 ${ }^{\circ}$ E.P.M.S.BTA.

${ }^{48}$ Adicional a la Dra. Aya fueron entrevistados los asistentes jurídicos de los Juzgados $9{ }^{\circ}$ (Fray Libardo Parra Rojas) y 11 (Sergio Chauta) E.P.M.S.

${ }^{49}$ Entrevista realizada el 7 de septiembre de 2012 en el J.1 $1^{\circ}$ E.P.M.S.BTA.

${ }^{50}$ Incluyendo aquí tanto los honorarios de abogado como el tiempo que requiere la defensa, la presión mediática y en definitiva su prestigio.

${ }^{51}$ Precisamente por el otorgamiento de sistemas de vigilancia electrónica como sustitutivo de la prisión a favor de alías "Kener" quien se fugó- se inició un proceso disciplinario en contra de los funcionarios judiciales relacionados con la concesión de este beneficio Cfr. http://m.eltiempo.com/colombia/detencion-domiciliaria-de-alias-kener-se-debio-a-dictamen-de-medicinalegal/7367600/home

${ }^{52}$ Se reitera que no se relacionan todas las providencias investigadas sino solo las referentes al objeto de esta investigación. vol.08, nº. 03, Rio de Janeiro, 2015.pp. 1271-1305 


\begin{tabular}{|c|c|c|c|c|}
\hline No & Radicado & $\begin{array}{l}\text { Fecha De La } \\
\text { Decisión }\end{array}$ & $\begin{array}{l}\text { Sistema De Enjuicimiento } \\
\text { Penal }\end{array}$ & Motivo De La Decisión \\
\hline 1. & 16734 & $05-01-12$ & L. $600 / 00$ & $\begin{array}{l}\text { No exige pago de la multa ni de los } \\
\text { perjuicios }\end{array}$ \\
\hline 2. & 80006 & $12-01-12$ & L. $600 / 00$ & $\begin{array}{l}\text { No exige pago de la multa ni de los } \\
\text { perjuicios }\end{array}$ \\
\hline 3. & 91278 & $23-01-12$ & L. $906 / 04$ & Paga multa (2.66 S.M.L.M.V.) ${ }^{53}$ \\
\hline 4. & 36882 & $30-01-12$ & L. $600 / 00$ & $\begin{array}{l}\text { No exige pago de la multa ni de los } \\
\text { perjuicios }\end{array}$ \\
\hline 5. & 58940 & $10-02-12$ & L. $600 / 00$ & $\begin{array}{l}\text { No exige pago de la multa ni de los } \\
\text { perjuicios }\end{array}$ \\
\hline 6. & 49845 & $20-02-12$ & L. $600 / 00$ & $\begin{array}{l}\text { No exige pago de la multa ni de los } \\
\text { perjuicios }\end{array}$ \\
\hline 7. & 42565 & 08-03-12 & L. $600 / 00$ & $\begin{array}{l}\text { No exige pago de la multa ni de los } \\
\text { perjuicios }\end{array}$ \\
\hline 8. & 71158 & $04-04-12$ & L. $600 / 00$ & $\begin{array}{l}\text { No exige pago de la multa ni de los } \\
\text { perjuicios }\end{array}$ \\
\hline 9. & 14183 & $03-04-12$ & L. $600 / 00$ & $\begin{array}{l}\text { No exige pago de la multa ni de los } \\
\text { perjuicios }\end{array}$ \\
\hline 10. & 64265 & $13-04-12$ & L. $600 / 00$ & $\begin{array}{l}\text { No exige pago de la multa ni de los } \\
\text { perjuicios }\end{array}$ \\
\hline 11. & 11627 & $13-04-12$ & L. $600 / 00$ & $\begin{array}{l}\text { No exige pago de la multa ni de los } \\
\text { perjuicios }\end{array}$ \\
\hline 12. & 67350 & $25-04-12$ & L. $600 / 00$ & $\begin{array}{l}\text { No exige pago de la multa ni de los } \\
\text { perjuicios }\end{array}$ \\
\hline 13. & 24835 & $07-05-12$ & L. $600 / 00$ & $\begin{array}{l}\text { No exige pago de la multa ni de los } \\
\text { perjuicios }\end{array}$ \\
\hline 14. & 90998 & $17-05-12$ & L. $600 / 00$ & $\begin{array}{l}\text { No exige pago de la multa ni de los } \\
\text { perjuicios }\end{array}$ \\
\hline 15. & 120612 & $24-05-12$ & L. $600 / 00$ & $\begin{array}{l}\text { No exige pago de la multa ni de los } \\
\text { perjuicios }\end{array}$ \\
\hline 16. & 82310 & $12-06-12$ & L. $600 / 00$ & $\begin{array}{l}\text { No exige pago de la multa ni de los } \\
\text { perjuicios }\end{array}$ \\
\hline 17. & 57328 & $19-06-12$ & L. $600 / 00$ & $\begin{array}{l}\text { No exige pago de la multa ni de los } \\
\text { perjuicios }\end{array}$ \\
\hline 18. & 14183 & $21-06-12$ & L. $600 / 00$ & $\begin{array}{l}\text { No exige pago de la multa ni de los } \\
\text { perjuicios }\end{array}$ \\
\hline 19. & 105879 & $28-06-12$ & L. $600 / 00$ & $\begin{array}{l}\text { No exige pago de la multa ni de los } \\
\text { perjuicios }\end{array}$ \\
\hline
\end{tabular}

Nótese que solo uno de los procesos relacionados corresponde al actual sistema de enjuiciamiento penal (No. 3.), donde se exige el pago de la multa y de los perjuicios, otorgándose este mecanismo por la acreditación efectiva de esta pena pecuniaria.

A continuación analizaré las providencias donde se niega la libertad condicional:

\footnotetext{
${ }^{53}$ Profiere la sentencia un Juez diferente (José Luis Clavijo)
} 
Niega Libertad Condicional

Se hallaron 194 providencias de las cuales 73 son negadas por no reunir todos los documentos, 63 por la gravedad de la conducta, 13 por no satisfacer el factor objetivo, 6 por prohibición expresa del artículo 68A del Código Penal -tener antecedentes penales-, 5 por prohibición expresa de la Ley 1121 de 2006 en tratándose de delitos de extorsión, 2 por prohibición expresa de la Ley 1098 en tratándose de delitos sexuales contra niños, niñas y adolescentes, 2 por mal comportamiento en el establecimiento de reclusión y 44 por no acreditar el pago de la multa o los perjuicios ${ }^{54}$. A continuación relaciono estas últimas:

\begin{tabular}{|c|c|c|c|c|}
\hline No & Radicado & $\begin{array}{l}\text { Fecha De La } \\
\text { Decisión }\end{array}$ & $\begin{array}{l}\text { Sistema De } \\
\text { Enjuicimiento } \\
\text { Penal }\end{array}$ & Motivo De La Decisión \\
\hline 1. & 95213 & $05-01-12$ & L.906/04 & No acredita pago de la multa \\
\hline 2. & 42380 & $19-01-12$ & L.906/04 & No acredita pago de la multa \\
\hline 3. & 110739 & $20-01-12$ & L.906/04 & No acredita pago de la multa \\
\hline 4. & 91593 & 20-01-12 & L.906/04 & No acredita pago de la multa \\
\hline 5. & 91593 & $15-02-12$ & L.906/04 & No acredita pago de la multa - reitera \\
\hline 6. & 22193 & $06-03-12$ & L.906/04 & No acredita pago de la multa \\
\hline 7. & 92297 & 06-03-12 & L.906/04 & No acredita pago de la multa \\
\hline 8. & 4601 & 07-03-12 & L.600/00 & No acredita pago de los perjuicios \\
\hline 9. & 36816 & 04-04-12 & L.906/04 & No acredita pago de la multa \\
\hline 10. & 91979 & 04-04-12 & L.906/04 & No acredita pago de la multa \\
\hline 11. & 107833 & $13-04-12$ & L.906/04 & $\begin{array}{c}\text { No acredita pago de la multa ni la resolución de buen } \\
\text { comportamiento. }\end{array}$ \\
\hline 12. & 105377 & $13-04-12$ & L.906/04 & No acredita pago de los perjuicios \\
\hline 13. & 107833 & $27-04-12$ & L.906/04 & $\begin{array}{l}\text { No acredita pago de la multa ni la resolución de buen } \\
\text { comportamiento. Advierte que la sentencia C-185/11 } \\
\text { no aplica para libertad condicional. }\end{array}$ \\
\hline 14. & 110739 & $10-05-12$ & L.906/04 & $\begin{array}{l}\text { No acredita pago de la multa. Advierte que la sentencia } \\
\text { C-185/11 no aplica para libertad condicional. }\end{array}$ \\
\hline 15. & 100684 & $14-05-12$ & L.906/04 & No acredita pago de la multa. \\
\hline 16. & 42380 & $15-05-12$ & L.906/04 & No acredita pago de la multa y gravedad del delito. \\
\hline 17. & 45249 & $29-05-12$ & L.906/04 & $\begin{array}{l}\text { No acredita pago de la multa. Advierte que la sentencia } \\
\text { C-185/11 no aplica para libertad condicional. }\end{array}$ \\
\hline 18. & 106741 & 29-05-12 & L.906/04 & No acredita pago de la multa \\
\hline 19. & 103391 & 04-06-12 & L.906/04 & $\begin{array}{c}\text { No acredita pago de la multa ni la resolución de buen } \\
\text { comportamiento. }\end{array}$ \\
\hline
\end{tabular}

\footnotetext{
${ }^{54}$ Adicionalmente 2 decisiones corresponden a la falta de otorgamiento de la suspensión condicional de la ejecución de la pena (artículo 63 del Código Penal) por encontrarse en firme tras haber sido estudiada en sede del Juzgado de Conocimiento y una que niega la prisión domiciliaria, sin embargo, estos sustitutos penales no hacen parte de la investigación.

Advertencia: La sumatoria de cada aspecto individual no corresponde con el número total de providencias analizadas atendiendo a que el motivo de la decisión se conjuga en algunas oportunidades, es decir, "no acredita pago de la multa y gravedad de la conducta" o "no reúne los documentos y no se satisface el requisito objetivo". Esta advertencia opera para los resultados subsiguientes correspondientes a los demás Juzgados analizados.
} 


\begin{tabular}{|c|c|c|c|c|}
\hline 20. & 71121 & $04-06-12$ & L.906/04 & $\begin{array}{l}\text { No acredita pago de la multa ni la resolución de buen } \\
\text { comportamiento. }\end{array}$ \\
\hline 21. & 43630 & 07-06-12 & L.906/04 & No acredita pago de la multa \\
\hline 22. & 100144 & $07-06-12$ & L.906/04 & $\begin{array}{l}\text { No acredita pago de la multa ni la resolución de buen } \\
\text { comportamiento. }\end{array}$ \\
\hline 23. & 42964 & $12-06-12$ & L.906/04 & $\begin{array}{c}\text { No acredita pago de la multa ni la resolución de buen } \\
\text { comportamiento. }\end{array}$ \\
\hline 24. & 45249 & $19-06-12$ & L.906/04 & No acredita pago de la multa \\
\hline 25. & 26677 & $19-06-12$ & L.906/04 & $\begin{array}{c}\text { No acredita pago de la multa ni la resolución de buen } \\
\text { comportamiento. }\end{array}$ \\
\hline 26. & 69554 & $21-06-12$ & L.906/04 & $\begin{array}{l}\text { No acredita pago de la multa ni la resolución de buen } \\
\text { comportamiento. }\end{array}$ \\
\hline 27. & 45249 & $28-06-12$ & L.906/04 & No acredita pago de la multa \\
\hline 28. & 100684 & $03-07-12$ & L.906/04 & $\begin{array}{l}\text { No acredita pago de la multa ni la resolución de buen } \\
\text { comportamiento. }\end{array}$ \\
\hline 29. & 65385 & $03-07-12$ & L.906/04 & $\begin{array}{c}\text { No acredita pago de la multa ni la resolución de buen } \\
\text { comportamiento. }\end{array}$ \\
\hline 30. & 100144 & $04-07-12$ & L.906/04 & No acredita pago de la multa \\
\hline 31. & 19755 & 04-07-12 & L.906/04 & $\begin{array}{c}\text { No acredita pago de la multa ni la resolución de buen } \\
\text { comportamiento. Tampoco se satisface el factor } \\
\text { objetivo }\end{array}$ \\
\hline 32. & 89060 & $11-07-12$ & L.906/04 & No acredita pago de la multa \\
\hline 33. & 90967 & $16-07-12$ & L.906/04 & $\begin{array}{l}\text { No acredita pago de la multa ni la resolución de buen } \\
\text { comportamiento. }\end{array}$ \\
\hline 34. & 46496 & $29-07-12$ & L.906/04 & No acredita pago de la multa \\
\hline 35. & 43630 & $31-07-12$ & L.906/04 & $\begin{array}{c}\text { No acredita pago de la multa ni la resolución de buen } \\
\text { comportamiento. }\end{array}$ \\
\hline 36. & 106307 & $31-07-12$ & L.906/04 & $\begin{array}{c}\text { No acredita pago de la multa ni la resolución de buen } \\
\text { comportamiento. }\end{array}$ \\
\hline 37. & 13709 & 01-08-12 & L.906/04 & $\begin{array}{c}\text { No acredita pago de la multa ni la resolución de buen } \\
\text { comportamiento. }\end{array}$ \\
\hline 38. & 97520 & $02-02-12$ & L.906/04 & $\begin{array}{c}\text { No acredita pago de la multa ni la resolución de buen } \\
\text { comportamiento. }\end{array}$ \\
\hline 39. & 106538 & 06-08-12 & L.906/04 & No acredita pago de la multa \\
\hline 40. & 81831 & $06-08-12$ & L.906/04 & No acredita pago de la multa \\
\hline 41. & 100684 & $06-08-12$ & L.906/04 & No acredita pago de la multa ni de los perjuicios \\
\hline 42. & 43630 & $06-08-12$ & L.906/04 & No acredita pago de la multa \\
\hline 43. & 63362 & $10-08-12$ & L. $906 / 04$ & $\begin{array}{l}\text { No acredita pago de la multa. Advierte que la sentencia } \\
\text { C- } 185 / 11 \text { no aplica para libertad condicional. }\end{array}$ \\
\hline 44. & 6217 & $10-08-12$ & L.906/04 & No acredita pago de los perjuicios \\
\hline
\end{tabular}


Este despacho es enfático en afirmar que la sentencia C-185/11 no tiene aplicación para efectos de otorgar el mecanismo de la libertad condicional, a pesar de lo consagrado en la sentencia T-309/12 proferida durante el lapso de las providencias analizadas en este Juzgado ${ }^{55}$.

\section{Concede Sistemas de Vigilancia Electrónica}

$\mathrm{Al}$ indagar sobre estas providencias la Juez $1^{\circ}$ E.P.M.S.BTA. manifestó que las solicitudes tendientes a obtener este beneficio son mínimas atendiendo a la negativa para su otorgamiento ${ }^{56}$ y efectivamente al revisar tanto los expedientes físicos como sus providencias, se encontró que sólo se materializó un otorgamiento de sistemas de vigilancia electrónica durante el período analizado (providencia del 26 de abril de 2012, proceso 92040) y esto por cuanto la decisión fue adoptada por el Juzgado 12 Penal del Circuito de Conocimiento en la sentencia $^{57}$, a pesar que el artículo $38 \mathrm{~A}$ del Código Penal le otorgaba esta competencia a los J.E.P.M.S. ${ }^{58}$

\section{Niega Sistemas De Vigilancia Electrónica}

Se localizaron 16 providencias de las cuales 12 son negadas en virtud del factor subjetivo - siendo peticiones subsidiarias a la solicitud de prisión domiciliaria -, 2 por tratarse de condenados reincidentes ${ }^{59}$ (una de estas igualmente porqué a pesar de haberse amortizado el pago de la multa, no se ha efectuado ningún pago) y una por encontrarse el delito de fabricación, tráfico y porte ilegal de armas, excluido para este otorgamiento. A continuación se relaciona la única providencia relacionada con el tema de investigación:

\begin{tabular}{|c|c|c|c|c|}
\hline No & Radicado & $\begin{array}{c}\text { Fecha De La } \\
\text { Decisión }\end{array}$ & $\begin{array}{c}\text { Sistema De } \\
\text { Enjuicimiento Penal }\end{array}$ & Motivo De La Decisión \\
\hline 1. & 90505 & $08-08-12$ & L.906/04 & $\begin{array}{c}\text { No cancela la multa a pesar de haberse amortizado la } \\
\text { misma. Adicionalmente el condenado es reincidente. }\end{array}$ \\
\hline
\end{tabular}

\footnotetext{
${ }^{55}$ La sentencia T-309 fue proferida el 24 de abril de 2012, sin embargo los pronunciamientos datados 27 de abril, 10 de mayo, 29 de mayo y 10 de agosto de 2012 (J.1E.P.M.S.BTA.) no la tienen en cuenta y manejan una interpretación diferente.

${ }^{56}$ Entrevista realizada el 12 de noviembre de 2012 en el J.1 ${ }^{\circ}$ E.P.M.S.BTA. "Tanto los abogados como los reclusos saben que este mecanismo no se concede"

${ }^{57}$ Providencia fechada 27 de octubre de 2009

${ }^{58} \mathrm{Si}$ bien es cierto, el artículo 38 de la Ley 906 de 2004 que regula la competencia de los J.E.P.M.S. no menciona este tópico, como si lo hace con la libertad condicional (numeral 3), es el mismo artículo 38A del Código Penal que expresamente en su encabezado, otorga esta capacidad de decisión a los despachos de E.P.M.S. Al indagarle a la Juez $1^{\circ}$ E.P.M.S. sobre esta atribución que se tomó el Juez de Conocimiento, sin tener competencia para ello, solo sonrió y no pudo dar una respuesta satisfactoria. Como dato curioso, cuando la funcionaria observó la boleta que ordena la vigilancia electrónica expresó su asombro en virtud que ella siempre niega este mecanismo.

${ }^{59}$ Bajo esta categoría se comprende en este texto, a las personas beneficiadas con anterioridad de algún mecanismo sustitutivo de la pena, revocado por incumplimiento de las obligaciones así como aquellos beneficiados por permisos administrativos que igualmente incumplieron.
} 
Archivo:J.9 de E.P.M.S BTA. (Descongestión) ${ }^{60}$

Durante la fase de recolección de datos el asistente jurídico de este Despacho se mostró muy interesado por los resultados preliminares anotados en mis apuntes, encontrando una variable repetitiva: la gravedad de la

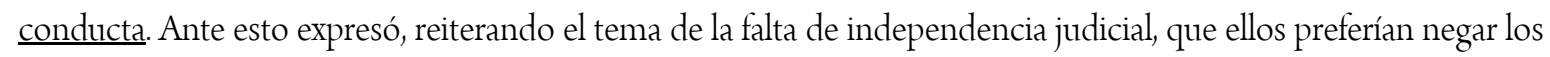
mecanismos sustitutivos, acudiendo al criterio de gravedad de la conducta - que resulta fácil de argumentar ya que en definitiva todas las conductas penales son graves -, que enfrentar un proceso disciplinario ${ }^{61}$.

A continuación se relacionan los hallazgos encontrados en este despacho:

Concede Libertad Condicional

Se encontraron 13 providencias, las cuales se relacionan a continuación, indicando el motivo de la decisión:

\begin{tabular}{|c|c|c|c|c|}
\hline No & Radicado & $\begin{array}{l}\text { Fecha de la } \\
\text { Decisión }\end{array}$ & $\begin{array}{l}\text { Sistema de } \\
\text { Enjuicimiento } \\
\text { Penal }\end{array}$ & Motivo de la Decisión \\
\hline 1. & 5491 & $05-10-12$ & L. 600/00 & No exige pago de la multa ni de los perjuicios \\
\hline 2. & 1435 & 03-10-12 & L. $600 / 00$ & No exige pago de la multa ni de los perjuicios \\
\hline 3 & 07174 & 28-09-12 & L. 906/04 & Se amortizó la multa con anterioridad \\
\hline 4. & 47619 & $27-09-12$ & L. $600 / 00$ & No exige pago de la multa ni de los perjuicios \\
\hline 5. & 114209 & $26-09-12$ & L. 906/04 & $\begin{array}{l}\text { El delito por el cual fue condenado (Hurto calificado y } \\
\text { agravado) no tiene pena de multa }\end{array}$ \\
\hline 6. & 63769 & $25-09-12$ & L. 906/04 & $\begin{array}{l}\text { El delito por el cual fue condenado (Hurto calificado y } \\
\text { agravado) no tiene pena de multa }\end{array}$ \\
\hline 7. & 90624 & $21-09-12$ & L. $600 / 00$ & No exige pago de la multa ni de los perjuicios \\
\hline 8. & 90791 & 19-09-12 & L. $600 / 00$ & No exige pago de la multa ni de los perjuicios \\
\hline 9. & 00296 & $18-09-12$ & L. $600 / 00$ & No exige pago de la multa ni de los perjuicios \\
\hline 10. & 07254 & $14-09-12$ & L. $600 / 00$ & No exige pago de la multa ni de los perjuicios \\
\hline 11. & 43787 & $14-09-12$ & L. $600 / 00$ & No exige pago de la multa ni de los perjuicios \\
\hline 12. & 17413 & $12-09-12$ & L. $600 / 00$ & No exige pago de la multa ni de los perjuicios \\
\hline 13. & 95110 & 04-09-12 & L.600/00 & $\begin{array}{l}\text { No exige pago de la multa ni de los perjuicios. Se advierte } \\
\text { que a pesar de tratarse de un delito sexual contra un } \\
\text { menor, para la fecha de los hechos no se encontraba } \\
\text { vigente la Ley } 1098 \text { de } 2006 .\end{array}$ \\
\hline
\end{tabular}

Nótese que dentro de los procesos regidos por el actual sistema de enjuiciamiento penal, su otorgamiento, relacionado con el tema de investigación, obedece a dos variables: (i) los delitos por los cuales

\footnotetext{
${ }^{60}$ Juez: Mario Fernando Narváez Fajardo

${ }^{61}$ Entrevista realizada al Dr. Fray Libardo Parra Rojas el 15 de noviembre de 2012 en el J.9².P.M.S.BTA. (Descongestión) vol.08, no. 03, Rio de Janeiro, 2015.pp. 1271-1305
} 
fueron condenados no consagran pena de multa (numerales 5. y 6.) o (ii) la multa fue cancelada a través de trabajo, bajo criterios de amortización ${ }^{62}$ (numeral 3.).

\section{Niega Libertad Condicional}

Se hallaron 73 providencias de las cuales 23 son negadas por la gravedad de la conducta, 17 por no reunir todos los documentos, 12 por no cumplirse el factor objetivo, 6 por prohibición expresa del artículo 68A del Código Penal -tener antecedentes penales-, 2 por prohibición expresa de la Ley 1098 en tratándose de delitos sexuales contra niños, niñas y adolescentes, 2 por mal comportamiento en el establecimiento de reclusión, 2 porqué ya había sido negado el subrogado por el J.E.P.M.S. que vigilaba la pena ${ }^{63}$, una por ser reincidente y 8 por no acreditar el pago de la multa. A continuación relaciono estas últimas:

\begin{tabular}{|c|c|c|c|c|}
\hline No & Radicado & $\begin{array}{c}\text { Fecha de la } \\
\text { Decisión }\end{array}$ & $\begin{array}{c}\text { Sistema de } \\
\text { Enjuicimiento Penal }\end{array}$ & Motivo de la Decisión \\
\hline 1. & 58324 & $03-10-12$ & L.906/04 & No acredita pago de la multa \\
\hline 2. & 73280 & $17-09-12$ & L.906/04 & No acredita pago de la multa \\
\hline 3. & 81036 & $17-09-12$ & L.906/04 & $\begin{array}{c}\text { No acredita pago de la multa y no se satisface } \\
\text { el requisito objetivo }\end{array}$ \\
\hline 4. & 107465 & $17-09-12$ & L.906/04 & No acredita pago de la multa \\
\hline 5. & 114185 & $10-09-12$ & L.906/04 & $\begin{array}{c}\text { No acredita pago de la multa. Autoriza } \\
\text { amortización de la multa }\end{array}$ \\
\hline 6. & 05453 & $27-08-12$ & L.906/04 & No acredita pago de la multa \\
\hline 7. & 80016 & $23-08-12$ & L.906/04 & No acredita pago de la multa \\
\hline 8. & 09556 & $23-08-12$ & L.906/04 & No acredita pago de la multa \\
\hline
\end{tabular}

Concede Sistemas de Vigilancia Electrónica

Desde su creación hasta las fechas en que se recaudó la información - 15 y 16 de noviembre de 2012- el J. $9^{\circ}$ E.P.M.S.BTA. (Descongestión) no otorgó ningún mecanismo sustitutivo de vigilancia electrónica ${ }^{64}$.

\footnotetext{
${ }^{62}$ Las multas pueden ser amortizadas en plazos o por trabajo social (numerales 6 y 7 , artículo 39 del Código Penal). En este último evento el condenado realiza ciertas labores autorizadas por el J.E.P.M.S. durante un lapso determinado por este último, a cambio de no cancelar dinerariamente la pena pecuniaria.

${ }^{63}$ Recordemos que estos Juzgados de Descongestión recibieron los procesos de otros Juzgados radicados que -en determinadas ocasiones- ya habían adoptado decisiones sobre estos casos.

${ }^{64}$ El asistente jurídico del despacho manifiesta que se encuentran pendientes de relacionar en el archivo varias providencias proferidas durante el período de paro judicial, cuyo trámite de secretaría no se ha podido llevar a cabo. Entrevista realizada el 15 de noviembre de 2012 en el J.9E.P.M.S.BTA. (Descongestión). Esta situación fue expresada por los tres J.E.P.M.S.BTA (Descongestión) explorados.
} 
Niega Sistemas de Vigilancia Electrónica

Se localizaron 9 providencias de las cuales 4 son negadas por no acreditar toda la documentación para este efecto, una en virtud del factor objetivo y otra por el factor subjetivo, una por encontrarse el delito excluido de este mecanismo (administración pública), una por tener antecedentes y otra porqué el J.13E.P.M.S.BTA. ya le había negado este mecanismo.

En ninguna de estas providencias se analizó la pena pecuniaria ni la eventual incapacidad de pago del condenado.

Archivo:J. 10 de E.P.M.S BTA. (Descongestión) ${ }^{65}$

Como se observará a continuación, este Juzgado era de los más garantistas frente al tema objeto de análisis y a pesar de que no se hace referencia a la sentencia T-309/12 se utilizaba la sentencia C-185/11 de manera extensiva para efectos de estudiar la libertad condicional:

Concede Libertad Condicional

Se encontraron 59 providencias que se relacionan a continuación, indicando el motivo de la decisión:

\begin{tabular}{|c|c|c|c|c|}
\hline No. & RADICADO & $\begin{array}{l}\text { FECHA DE } \\
\text { LA } \\
\text { DECISIÓN }\end{array}$ & $\begin{array}{l}\text { SISTEMA DE } \\
\text { ENJUICIMIENTO } \\
\text { PENAL }\end{array}$ & MOTIVO DE LADECISIÓN \\
\hline 1. & 80937 & $30-10-12$ & L.906/04 & $\begin{array}{l}\text { El delito por el cual fue condenado (Hurto } \\
\text { calificado y agravado) no tiene pena de multa }\end{array}$ \\
\hline 2. & 63169 & $30-10-12$ & L.906/04 & $\begin{array}{l}\text { El delito por el cual fue condenado (Hurto } \\
\text { calificado y agravado) no tiene pena de multa }\end{array}$ \\
\hline 3. & 98309 & $30-10-12$ & L.600/00 & No exige pago de la multa ni de los perjuicios \\
\hline 4. & 105385 & $30-10-12$ & L.600/00 & No exige pago de la multa ni de los perjuicios \\
\hline 5. & 51916 & $30-10-12$ & L.600/00 & No exige pago de la multa ni de los perjuicios \\
\hline 6. & 14583 & $30-10-12$ & L.906/04 & $\begin{array}{l}\text { El delito por el cual fue condenado (Hurto } \\
\text { calificado y agravado) no tiene pena de multa }\end{array}$ \\
\hline 7. & 107065 & $30-10-12$ & L.906/04 & $\begin{array}{l}\text { El delito por el cual fue condenado (Hurto } \\
\text { calificado y agravado) no tiene pena de multa }\end{array}$ \\
\hline 8. & 109116 & $30-10-12$ & L.906/04 & $\begin{array}{l}\text { Se amortizó el pago de la multa por trabajo } \\
\text { social en el establecimiento penitenciario }\end{array}$ \\
\hline 9. & 106684 & $30-10-12$ & L.906/04 & $\begin{array}{l}\text { El delito por el cual fue condenado (Hurto } \\
\text { calificado y agravado) no tiene pena de multa }\end{array}$ \\
\hline
\end{tabular}

\footnotetext{
${ }^{65}$ Juez: Orlando Fierro Perdomo. El Dr. Fierro Perdomo fungía como magistrado del Tribunal Superior de Bogotá -Sala Penalpara el año 2011 y fue el encargado de decidir la medida de aseguramiento contra el ex - ministro Andrés Felipe Arias dentro del escándalo AIS. Ver http://www.lanacion.com.co/2011/08/07/magistrado-que-encarcelo-a-arias-teme-por-su-vida/
} vol.08, nº. 03, Rio de Janeiro, 2015.pp. 1271-1305 


\begin{tabular}{|c|c|c|c|c|}
\hline 10. & 71289 & $30-10-12$ & L.600/00 & No exige pago de la multa ni de los perjuicios \\
\hline 11. & 110975 & $24-10-12$ & L.906/04 & $\begin{array}{l}\text { El delito por el cual fue condenado (Hurto } \\
\text { calificado y agravado) no tiene pena de multa }\end{array}$ \\
\hline 12. & 35259 & $24-10-12$ & L.600/00 & $\begin{array}{l}\text { No exige pago de la multa ni de los perjuicios. } \\
\text { Se advierte que a pesar de tratarse de un delito } \\
\text { sexual contra un menor, para la fecha de los } \\
\text { hechos no se encontraba vigente la Ley } 1098 \\
\text { de } 2006 \text {. }\end{array}$ \\
\hline 13. & 68238 & $23-10-12$ & L.600/00 & No exige pago de la multa ni de los perjuicios \\
\hline 14. & 3273 & $17-10-12$ & L.600/00 & No exige pago de la multa ni de los perjuicios \\
\hline 15. & 77761 & $10-10-12$ & L.906/04 & Se amortizó la pena de multa por trabajo social \\
\hline 16. & 101850 & 09-10-12 & L.906/04 & $\begin{array}{l}\text { El delito por el cual fue condenado (Uso de } \\
\text { documento público falso) no tiene pena de } \\
\text { multa }\end{array}$ \\
\hline 17. & 11332 & 09-10-12 & L.906/04 & $\begin{array}{l}\text { El delito por el cual fue condenado (Hurto } \\
\text { calificado y agravado) no tiene pena de multa }\end{array}$ \\
\hline 18. & 11098 & $09-10-12$ & L.906/04 & $\begin{array}{l}\text { El delito por el cual fue condenado (Hurto } \\
\text { calificado y agravado) no tiene pena de multa }\end{array}$ \\
\hline 19. & 93181 & $09-10-12$ & L.906/04 & $\begin{array}{l}\text { El delito por el cual fue condenado (Hurto } \\
\text { calificado y agravado) no tiene pena de multa }\end{array}$ \\
\hline 20. & 16004 & 09-10-12 & L.600/00 & No exige pago de la multa ni de los perjuicios \\
\hline 21. & 99445 & $09-10-12$ & L.906/04 & $\begin{array}{l}\text { Se demostró incapacidad económica. Se acoge } \\
\text { sentencia C-185/11 }\end{array}$ \\
\hline 22. & 77518 & $03-10-12$ & L.906/04 & Se pagó la multa \\
\hline 23. & 49813 & $02-10-12$ & L.906/04 & Se amortizó la pena de multa por trabajo social \\
\hline 24. & 99247 & $28-09-12$ & L.906/04 & Se amortizó la pena de multa por trabajo social \\
\hline 25. & 70536 & $26-09-12$ & L.906/04 & Se pagó la multa \\
\hline 26. & 108830 & 27-09-12 & L. $906 / 04$ & $\begin{array}{l}\text { El delito por el cual fue condenado (Hurto } \\
\text { calificado y agravado) no tiene pena de multa }\end{array}$ \\
\hline 27. & 93181 & $27-09-12$ & L.906/04 & $\begin{array}{l}\text { El delito por el cual fue condenado (Hurto } \\
\text { calificado y agravado) no tiene pena de multa }\end{array}$ \\
\hline 28. & 62966 & 26-09-12 & L.906/04 & $\begin{array}{l}\text { El delito por el cual fue condenado (Hurto } \\
\text { calificado y agravado) no tiene pena de multa }\end{array}$ \\
\hline 29. & 84285 & $26-09-12$ & L.600/00 & No exige pago de la multa ni de los perjuicios \\
\hline 30. & 109242 & 24-09-12 & L.906/04 & $\begin{array}{l}\text { El delito por el cual fue condenado (tráfico de } \\
\text { moneda falsificada) no tiene pena de multa }\end{array}$ \\
\hline 31. & 43141 & $19-09-12$ & L.600/00 & No exige pago de la multa ni de los perjuicios \\
\hline 32. & 19886 & $21-09-12$ & L.600/00 & No exige pago de la multa ni de los perjuicios \\
\hline 33. & 99059 & 21-09-12 & L.906/04 & $\begin{array}{l}\text { El delito por el cual fue condenado (Hurto } \\
\text { calificado y agravado) no tiene pena de multa }\end{array}$ \\
\hline 34. & 63475 & 21-09-12 & L. $600 / 00$ & $\begin{array}{l}\text { No exige pago de la multa ni de los perjuicios. } \\
\text { Se advierte que a pesar de tratarse de un delito } \\
\text { sexual contra un menor, para la fecha de los } \\
\text { hechos no se encontraba vigente la Ley } 1098 \\
\text { de } 2006 \text {. }\end{array}$ \\
\hline 35. & 11877 & $21-09-12$ & L.906/04 & $\begin{array}{l}\text { El delito por el cual fue condenado (Hurto } \\
\text { calificado y agravado) no tiene pena de multa }\end{array}$ \\
\hline
\end{tabular}




\begin{tabular}{|c|c|c|c|c|}
\hline 36. & 93148 & $20-09-12$ & L.906/04 & $\begin{array}{l}\text { El delito por el cual fue condenado (falsedad } \\
\text { material en documento público) no tiene pena } \\
\text { de multa }\end{array}$ \\
\hline 37. & 54887 & 20-09-12 & L.906/04 & $\begin{array}{l}\text { El delito por el cual fue condenado (Hurto } \\
\text { calificado y agravado) no tiene pena de multa. } \\
\text { Este mecanismo había sido negado por el J. } 12 \\
\text { E.P.M.S.BTA. por la prohibición del artículo } \\
68 \text { A del Código penal, sin embargo este } \\
\text { despacho considera que la misma no aplica } \\
\text { para este caso en virtud de la aceptación de } \\
\text { cargos }\end{array}$ \\
\hline 38. & 100347 & $20-09-12$ & L.906/04 & $\begin{array}{l}\text { El delito por el cual fue condenado (tentativa } \\
\text { de Homicidio) no tiene pena de multa. Este } \\
\text { mecanismo había sido negado por el J. } 1^{\circ} \\
\text { E.P.M.S.BTA. por la gravedad de la conducta, } \\
\text { sin embargo este despacho valoró la tentativa, } \\
\text { la aceptación de cargos y la indemnización de } \\
\text { la víctima. }\end{array}$ \\
\hline 39. & 110752 & $19-09-12$ & L.906/04 & $\begin{array}{l}\text { El delito por el cual fue condenado } \\
\text { (Fabricación tráfico y porte ilegal de armas) no } \\
\text { tiene pena de multa }\end{array}$ \\
\hline 40. & 90881 & $18-09-12$ & L.906/04 & $\begin{array}{l}\text { El delito por el cual fue condenado (Hurto } \\
\text { calificado y agravado) no tiene pena de multa }\end{array}$ \\
\hline 41. & 99101 & $17-09-12$ & L.600/00 & No exige pago de la multa ni de los perjuicios \\
\hline 42. & 32121 & $14-09-12$ & L.600/00 & No exige pago de la multa ni de los perjuicios \\
\hline 43. & 29287 & $14-09-12$ & L.906/04 & $\begin{array}{l}\text { El delito por el cual fue condenado } \\
\text { (Fabricación tráfico y porte ilegal de armas) no } \\
\text { tiene pena de multa }\end{array}$ \\
\hline 44. & 29287 & $14-09-12$ & L.906/04 & $\begin{array}{l}\text { El delito por el cual fue condenado } \\
\text { (Fabricación tráfico y porte ilegal de armas) no } \\
\text { tiene pena de multa }\end{array}$ \\
\hline 45. & 109717 & $13-09-12$ & L.906/04 & $\begin{array}{l}\text { El delito por el cual fue condenado (Hurto } \\
\text { calificado y agravado) no tiene pena de multa }\end{array}$ \\
\hline 46. & 87269 & $12-09-12$ & L.600/00 & No exige pago de la multa ni de los perjuicios \\
\hline 47. & 86774 & $12-09-12$ & L.600/00 & No exige pago de la multa ni de los perjuicios \\
\hline 48. & 84966 & $11-09-12$ & L.600/00 & $\begin{array}{l}\text { No exige pago de la multa ni de los perjuicios. } \\
\text { Se advierte que a pesar de tratarse de un delito } \\
\text { sexual contra un menor, para la fecha de los } \\
\text { hechos no se encontraba vigente la Ley } 1098 \\
\text { de } 2006 \text {. }\end{array}$ \\
\hline 49. & 100599 & $10-09-12$ & L.906/04 & $\begin{array}{l}\text { El delito por el cual fue condenado (Hurto } \\
\text { calificado y agravado) no tiene pena de multa }\end{array}$ \\
\hline 50. & 51516 & 06-09-12 & L.906/04 & $\begin{array}{l}\text { El delito por el cual fue condenado (Hurto } \\
\text { calificado y agravado) no tiene pena de multa }\end{array}$ \\
\hline 51. & 97353 & $05-09-12$ & L.906/04 & $\begin{array}{l}\text { El delito por el cual fue condenado (Hurto } \\
\text { calificado y agravado) no tiene pena de multa }\end{array}$ \\
\hline 52. & 83335 & 03-09-12 & L.906/04 & $\begin{array}{l}\text { El delito por el cual fue condenado (Tentativa } \\
\text { de homicidio y Fabricación tráfico y porte }\end{array}$ \\
\hline
\end{tabular}




\begin{tabular}{|l|l|l|l|l|}
\hline 53. & 42966 & $31-08-12$ & L.906/04 & $\begin{array}{l}\text { ilegal de armas) no tiene pena de multa } \\
\text { El delito por el cual fue condenado (tentativa } \\
\text { de Hurto calificado) no tiene pena de multa }\end{array}$ \\
\hline 54. & 71907 & $31-08-12$ & L.906/04 & $\begin{array}{l}\text { Se amortizó la pena de multa por trabajo social } \\
\text { El delito por el cual fue condenado (Hurto } \\
\text { calificado y agravado) no tiene pena de multa }\end{array}$ \\
\hline 55. & 95318 & $31-08-12$ & L.906/04 & $\begin{array}{l}\text { No exige pago de la multa ni de los perjuicios } \\
\text { El delito por el cual fue condenado (Hurto } \\
\text { calificado y agravado) no tiene pena de multa }\end{array}$ \\
\hline 56. & 22777 & $31-08-12$ & L.600/00 & La multa se encuentra en cobro coactivo \\
\hline 57. & 101790 & $30-08-12$ & L.906/04 & $\begin{array}{l}\text { El delito por el cual fue condenado (Hurto } \\
\text { calificado y agravado) no tiene pena de multa }\end{array}$ \\
\hline 58. & 95461 & $30-08-12$ & L.906/04 & L.906/04 \\
\hline 59. & 66400 & $28-08-12$ & &
\end{tabular}

En este despacho encontramos otras variables a las ya anotadas con anterioridad, como puede observarse en los numerales iii., iv. y v.: (i) los delitos por los cuales fueron condenados no consagran pena de multa, (ii) la multa fue cancelada a través de trabajo, bajo criterios de amortización, (iii) la multa fue cancelada de manera efectiva, (iv) $\underline{\text { se }}$ demostró la incapacidad económica -siguiendo los lineamientos de la sentencia C-185/11 y (v) la multa se encuentra en cobro coactivo. Estas dos últimas no son utilizadas por ninguno de los otros despachos examinados.

La tesis de este despacho sobre la concesión de beneficios es más flexible, al punto que aplicaban el precedente jurisprudencial fuertemente, aunado a que inclusive tiene en cuenta la situación de cobro coactivo para conceder la libertad condicional. Esta alternativa podría haberse aplicado a la situación de muchos reclusos y hubiese representado una solución significativa a la situación de hacinamiento carcelario, máxime cuando la multa termina siendo una obligación patrimonial que no debe impedir el ejercicio de otros derechos, como la libertad física y la libertad de locomoción, debiendo afectarse el patrimonio del condenado pero no la posibilidad de salir del establecimiento penitenciario.

- NIEGA LIBERTAD CONDICIONAL. Se localizaron 143 providencias de las cuales 41 son negadas no reunir todos los documentos, 32 por la gravedad de la conducta, 24 por no reunir el factor objetivo, 6 por prohibición expresa de la Ley 1098 en tratándose de delitos sexuales contra niños, niñas y adolescentes, 4 por mal comportamiento en el establecimiento de reclusión, 3 por prohibición expresa del artículo 68A del Código Penal -tener antecedentes penales-, 3 por ser reincidentes, una por prohibición expresa de la Ley 1121 de 2006 en tratándose de delitos de extorsión, y 18 por no acreditar el pago de la multa. A continuación relaciono estas últimas: 


\begin{tabular}{|c|c|c|c|c|}
\hline $\mathrm{N}^{\circ}$ & Radicado & $\begin{array}{c}\text { Fecha De La } \\
\text { Decisión }\end{array}$ & $\begin{array}{c}\text { Sistema De } \\
\text { Enjuicimiento Penal }\end{array}$ & Motivo De La Decisión \\
\hline 1. & 83612 & $10-10-12$ & L.906/04 & $\begin{array}{l}\text { No acredita pago de la multa ni demostró } \\
\text { insolvencia. Se hace expresa mención a la } \\
\text { sentencia C-185/11 }\end{array}$ \\
\hline 2. & 109901 & $09-10-12$ & L.906/04 & No acredita pago de la multa \\
\hline 3. & 67788 & 09-10-12 & L.906/04 & No acredita pago de la multa \\
\hline 4. & 101955 & 03-10-12 & L.906/04 & $\begin{array}{l}\text { No se demostró incapacidad económica. Cita } \\
\text { sentencia C-185/11 }\end{array}$ \\
\hline 5. & 34790 & $01-10-12$ & L.906/04 & $\begin{array}{l}\text { No se demostró incapacidad económica. Cita } \\
\text { sentencia C-185/11 }\end{array}$ \\
\hline 6. & 99445 & $01-10-12$ & L.906/04 & $\begin{array}{l}\text { No se demostró incapacidad económica. Cita } \\
\text { sentencia C-185/11 }\end{array}$ \\
\hline 7. & 67543 & $27-09-12$ & L.906/04 & No acredita pago de la multa \\
\hline 8. & 88415 & $26-09-12$ & L.906/04 & $\begin{array}{l}\text { No se demostró incapacidad económica. Cita } \\
\text { sentencia C-185/11 }\end{array}$ \\
\hline 9. & 110135 & $24-09-12$ & L.906/04 & $\begin{array}{c}\text { No acredita pago de la multa. Ya se había } \\
\text { negado con anterioridad la amortización de la } \\
\text { misma }\end{array}$ \\
\hline 10. & 91318 & 24-09-12 & L.906/04 & $\begin{array}{l}\text { No acredita pago de la multa ni demostró } \\
\text { insolvencia. Se hace expresa mención a la } \\
\text { sentencia C-185/11 }\end{array}$ \\
\hline 11. & 14094 & $20-09-12$ & L.906/04 & $\begin{array}{l}\text { No acredita pago de la multa, la conducta es } \\
\text { grave y no se adjunta toda la documentación. }\end{array}$ \\
\hline 12. & 92858 & 19-08-12 & L.906/04 & No acredita pago de la multa \\
\hline 13. & 84403 & $18-08-12$ & L.906/04 & $\begin{array}{l}\text { No acredita pago de la multa. Ya se había } \\
\text { negado con anterioridad la amortización de la } \\
\text { misma }\end{array}$ \\
\hline 14. & 96772 & $14-09-12$ & L.906/04 & No acredita pago de la multa \\
\hline 15. & 103105 & $13-09-12$ & L.906/04 & No acredita pago de la multa \\
\hline 16. & 52173 & $13-09-12$ & L.906/04 & $\begin{array}{l}\text { No acredita pago de la multa. Ya se había } \\
\text { negado con anterioridad la amortización de la }\end{array}$ \\
\hline
\end{tabular}




\begin{tabular}{|c|c|c|c|c|}
\hline 17. & 44556 & $06-09-12$ & L.906/04 & misma \\
\hline 18. & 106596 & $05-09-12$ & L.906/04 & $\begin{array}{c}\text { No acredita pago de la multa. Ya se había } \\
\text { sentencia C-185/11 } \\
\text { negado con anterioridad la amortización de la } \\
\text { misma }\end{array}$ \\
\hline
\end{tabular}

Según el asistente jurídico de este despacho, la carga de la prueba para la demostración de esta situación de insolvencia está en cabeza del condenado, por ello, siempre y cuando éste demuestre que no tiene capacidad económica, por ejemplo a través de certificación de la oficina de registro e instrumentos públicos sobre la carencia de bienes o de los servicios integrales para la movilidad -SIM- sobre la no titularidad de rodantes, se concede a su favor este mecanismo sustitutivo ${ }^{66}$.

Concede Sistemas de Vigilancia Electrónica

Se encontraron 4 providencias que se relacionan a continuación:

\begin{tabular}{|c|c|c|c|c|}
\hline No & Radicado & $\begin{array}{l}\text { Fecha De La } \\
\text { Decisión }\end{array}$ & $\begin{array}{c}\text { Sistema De } \\
\text { Enjuicimiento Penal }\end{array}$ & Motivo De La Decisión \\
\hline 1. & 107329 & $09-11-12$ & L. $906 / 04$ & $\begin{array}{l}\text { El delito por el cual fue condenado (Hurto } \\
\text { calificado y agravado) no tiene pena de multa }\end{array}$ \\
\hline 2. & 11840 & 01-11-12 & L. $906 / 04$ & $\begin{array}{l}\text { El delito por el cual fue condenado (uso de } \\
\text { documento falso) no tiene pena de multa }\end{array}$ \\
\hline 3. & 11840 & $09-10-12$ & L. $906 / 04$ & $\begin{array}{l}\text { El delito por el cual fue condenado (Falso } \\
\text { testimonio) no tiene pena de multa }\end{array}$ \\
\hline 4. & 12844 & $27-09-12$ & L. $906 / 04$ & $\begin{array}{l}\text { El delito por el cual fue condenado (Hurto } \\
\text { calificado y agravado) no tiene pena de multa }\end{array}$ \\
\hline
\end{tabular}

No se concedieron sistemas de vigilancia electrónica en tratándose de delitos que contengan pena de multa.

\section{Niega Sistemas De Vigilancia Electrónica}

Se hallaron 9 providencias de las cuales 4 fueron negadas por no cumplirse el requisito objetivo, 4 porqué los delitos por los cuales fueron condenados se encuentran excluidos de este beneficio (porte ilegal de armas y porte de estupefacientes) y una por la gravedad de la conducta. Ninguno fue negado en virtud de la multa.

\footnotetext{
${ }^{66}$ Entrevista realizada el 16 de noviembre de 2012 en el J.10E.P.M.S.BTA. (Descongestión) vol.08, nº. 03, Rio de Janeiro, 2015.pp. 1271-1305
} 


\section{Archivo:J. 11 de E.P.M.S BTA. (Descongestión) ${ }^{67}$}

En este despacho, al igual que en el J. $9^{\circ}$ E.P.M.S. BTA. (Descongestión), el asistente jurídico me anticipó que la negativa de los mecanismos sustitutivos de la pena de prisión obedece en gran medida al análisis de la gravedad de la conducta y la inexistencia de un parámetro para establecer esa gravedad, quedando este criterio al arbitrio del Juez, graficando esta situación de la siguiente manera: si un Juez padeció el hurto de su automotor esta conducta será gravísima, contrario a lo que ocurre frente a un Juez que no tiene carro ${ }^{68}$.

A continuación los resultados obtenidos en este despacho:

\section{Concede Libertad Condicional}

Se encontraron 14 providencias que se relacionan a continuación, indicando el motivo de la decisión:

\begin{tabular}{|c|c|c|c|c|}
\hline No & Radicado & $\begin{array}{c}\text { Fecha de la } \\
\text { Decisión }\end{array}$ & $\begin{array}{c}\text { Sistema de Enjuicimiento } \\
\text { Penal }\end{array}$ & \multicolumn{1}{|c|}{ Motivo de la Decisión } \\
\hline 1. & 71745 & $16-10-12$ & L. $600 / 00$ & No exige pago de la multa ni de los perjuicios \\
\hline 2. & 7134 & $02-10-12$ & L. $600 / 00$ & No exige pago de la multa ni de los perjuicios \\
\hline 3. & 65560 & $19-09-12$ & L. $600 / 00$ & No exige pago de la multa ni de los perjuicios \\
\hline 4. & $65560^{69}$ & $19-09-12$ & L. $600 / 00$ & No exige pago de la multa ni de los perjuicios \\
\hline 5. & 25356 & $19-09-12$ & L. $600 / 00$ & No exige pago de la multa ni de los perjuicios \\
\hline 6. & 60697 & $18-09-12$ & L. $600 / 00$ & No exige pago de la multa ni de los perjuicios \\
\hline 7. & 86628 & $18-09-12$ & L. $600 / 00$ & No exige pago de la multa ni de los perjuicios \\
\hline 8. & 62033 & $17-09-12$ & L. $600 / 00$ & No exige pago de la multa ni de los perjuicios \\
\hline 9. & 114479 & $14-09-12$ & L. $600 / 00$ & No exige pago de la multa ni de los perjuicios \\
\hline 10. & 39404 & $06-09-12$ & L. $600 / 00$ & No exige pago de la multa ni de los perjuicios \\
\hline 11. & 33497 & $05-09-12$ & L. $600 / 00$ & No exige pago de la multa ni de los perjuicios \\
\hline 12. & 10127 & $28-08-12$ & L. $600 / 00$ & No exige pago de la multa ni de los perjuicios \\
\hline 13. & 18134 & $27-08-12$ & L. $600 / 00$ & No exige pago de la multa ni de los perjuicios \\
\hline 14. & 88039 & $27-08-12$ & L. $600 / 00$ & No exige pago de la multa ni de los perjuicios \\
\hline
\end{tabular}

Como se puede observar, este despacho no había otorgado libertad condicional a ningún condenado cuyo sistema de enjuiciamiento penal corresponde al regido por la ley 906 de 2004.

\footnotetext{
${ }^{67}$ Juez: Eduardo Moyano Vargas

${ }^{68}$ Entrevista realizada al Dr. Sergio Chauta el día 17 de noviembre de 2012 en el J.11 E.P.M.S.BTA. (Descongestión). También anticipó tener pendientes de decisión varios procesos regidos por la ley 906 de 2004, relacionados con solicitudes de mecanis mos sustitutivos de la pena de prisión, que muy probablemente serían negados por la gravedad de la conducta.

${ }^{69}$ Las casillas 3 y 4 tienen el mismo número de radicación porqué se trata del mismo proceso pero las decisiones adoptadas benefician a diferentes condenados: Pedro Julio Rendón Buitrago (Interlocutorio 2012-0072) y Luis Arcadio Bustos Rubio (Interlocutorio 2012-0071)
} 


\section{Niega Libertad Condicional}

Se hallaron 48 providencias de las cuales 36 son negadas por la gravedad de la conducta, 15 por prohibición expresa del artículo 68A del Código Penal -tener antecedentes penales-, 5 por no reunir el factor objetivo, 3 por prohibición expresa de la Ley 1121 de 2006 en tratándose de delitos de extorsión y 3 por no acreditar el pago de la multa. A continuación relaciono estas últimas:

\begin{tabular}{|c|c|c|c|c|}
\hline No & Radicado & $\begin{array}{c}\text { Fecha de la } \\
\text { Decisión }\end{array}$ & $\begin{array}{c}\text { Sistema de } \\
\text { Enjuicimiento Penal }\end{array}$ & Motivo de la Decisión \\
\hline 1. & 99950 & $22-10-12$ & Ley $906 / 04$ & No acredita pago de la multa \\
\hline 2. & 11319 & $21-09-12$ & Ley $906 / 04$ & $\begin{array}{c}\text { No se pronuncia sobre la insolvencia económica para el } \\
\text { pago de la multa porqué se negó el subrogado por la } \\
\text { gravedad de la conducta. }\end{array}$ \\
\hline 3. & $74733^{70}$ & $30-08-12$ & Ley 906/04 & No acredita pago de la multa y gravedad de la conducta \\
\hline
\end{tabular}

Concede Sistemas de Vigilancia Electrónica

Dentro de las providencias indagadas el J. 11 E.P.M.S.BTA. (Descongestión) no otorgó ningún mecanismo sustitutivo de vigilancia electrónica.

Niega Sistemas de Vigilancia Electrónica

Se encontró solo una providencia donde se niega el mecanismo por la gravedad de la conducta y por no acreditar el pago de la multa, ni los perjuicios:

\begin{tabular}{|c|c|c|c|c|}
\hline No & Radicado & $\begin{array}{c}\text { Fecha de la } \\
\text { Decisión }\end{array}$ & $\begin{array}{c}\text { Sistema de } \\
\text { Enjuicimiento Penal }\end{array}$ & Motivo de la Decisión \\
\hline 1. & 41881 & $18-10-12$ & Ley 600/00 & $\begin{array}{c}\text { No cancela la multa ni los perjuicios y no } \\
\text { demuestra incapacidad económica. }\end{array}$ \\
\hline
\end{tabular}

Como se puede observar a través de los resultados de esta investigación, los J.E.P.M.S.BTA. mantenían, mayoritariamente, un criterio restrictivo en materia de concesión de mecanismos sustitutivos de la pena de prisión, sin tener en cuenta la situación de hacinamiento carcelario y otorgando una mayor relevancia al miedo disciplinario.

\footnotetext{
${ }^{70}$ En este proceso el sentenciado es el ex - Juez $5^{\circ}$ Penal Municipal de Bogotá (Luis Eduardo Beltrán Farias) quien fue condenado por el delito de prevaricato por acción agravado. Al respecto ver: http://www.elespectador.com/articulo185476-niegan-libertadjuez-luis-eduardo-beltran-farias
} 
A manera de consolidado general, podemos observar como solo se otorgaron 5 sistemas de vigilancia electrónica durante el período estudiado ${ }^{71}$, respecto de los 4 despachos judiciales explorados, y 115 libertades condicionales, baremo que explica el caos actual de las prisiones del país.

\section{CONCLUSIONES}

El artículo $10^{\circ}$ del Pacto Internacional de Derechos Civiles y Políticos, entre otros mandatos relacionados con las garantías del sistema penitenciario y carcelario, establece que el tratamiento intramural tiene la finalidad de reformar y readaptar socialmente a los penados. Estas finalidades deben ser evaluadas por los funcionarios del establecimiento donde se encuentra recluido el condenado y en caso de haber observado una buena conducta y satisfacer un tiempo real y efectivo privado de la libertad, debe contar con alternativas que premien su buen comportamiento al igual que incentive a su compañeros a seguir este buen ejemplo.

En este escenario, la figura del Juez de E.P.M.S. debe ser la de constatar los requisitos objetivo y subjetivo -legalmente establecidos - referentes a cada mecanismo sustitutivo sin que vuelva a valorar la conducta ya judicializada en la sentencia condenatoria.

La gravedad de la conducta no debe hacer parte de este análisis ya que precisamente esto motivó su condena, la eventual elevación en el proceso de dosimetría penal y la negativa de subrogados penales en sede de los Juzgados de Conocimiento. Tampoco deben exigirse obligaciones pecuniarias (multa y perjuicios) que afectan la órbita patrimonial del condenado pero que lamentablemente, en la fase de ejecución del proceso, se hacen extensibles a su ámbito personal, afectando la libertad física y su libre locomoción, en detrimento colateral del sistema penitenciario, hoy en día colapsado.

Precisamente, una novedad de la ley 1709 fue eliminar el término "gravedad" dejando vigente la "valoración de la conducta punible" como requisito inicial que deberá agotar el J.E.P.M.S. para la concesión del subrogado sub examine. Con base en esto vale la pena preguntarnos ¿Resulta significativa la modificación legislativa realizada por el legislador al eliminar el término "gravedad", dejando vigente el análisis previo de la conducta punible? La respuesta negativa a este interrogante está sustentada en la visión de los directamente afectados y el criterio de los operadores jurídicos que confirman su dicho.

Así, en el trabajo de campo realizado por el Grupo de Prisiones de la Universidad de los Andes en el Establecimiento Penitenciario y Carcelario "La Modelo" de la ciudad de Bogotá (2014), hemos logrado constatar, con base en las manifestaciones de los reclusos, que los J.E.P.M.S., continúan negando la libertad condicional con sustento en el análisis de la conducta punible y la argumentación referente a su impacto en la sociedad y la víctima,

\footnotetext{
${ }^{71}$ Uno de los cuales había sido otorgado por el Juzgado de conocimiento en aparente falta de competencia (supra 1. Archivo: J. $1^{\circ}$ de E.P.M.S BTA. (Descongestión) -Concede sistemas de vigilancia electrónica)
} vol.08, nº. 03, Rio de Janeiro, 2015.pp. 1271-1305 
así como la necesidad del tratamiento penitenciario, con independencia del concepto favorable emitido por el centro de reclusión.

Congruente con lo anterior, los Juzgados continúan negando la libertad condicional, por los motivos arriba anotados, algunos cuidándose de no utilizar el término "gravedad" al valorar la conducta punible y mutando su argumentación hacia la "modalidad" de como acaeció el delito, mientras que otros continúan manejando el formato vigente antes de la reforma, cambiando únicamente la cita correspondiente a la normatividad aplicable ${ }^{72}$.

En este sentido, el pasado 7 de marzo de 2014, se entrevistó a un funcionario judicial ${ }^{73}$, indagando sobre la modificación introducida por la ley 1709 y la metodología adoptada por los J.E.P.M.S., quien al respecto, nos manifestó: "( ... ) el tema se está manejando igual que antes, con aplicación de la sentencia C-194 de 2005. Es más, se considera que como se eliminó el término "gravedad", la valoración puede ser más amplia y abarcar, por ejemplo, la modalidad de la conducta, pero siempre con sujeción a lo considerado por el sentenciador".

En similar sentido, otro funcionario judicial ${ }^{74}$ había manifestado lo siguiente: “ ( ... ) de todas formas se dejó la previa valoración de la conducta que nos obliga a hacer ese estudio y así pues, por libertad condicional no es mucho lo que sale (...) si no lo hacemos entonces salen a cometer peores delitos y dicen que somos los responsables de eso".

La argumentación esgrimida por los J.E.P.M.S. resulta incoherente con el espíritu de la ley 1709 que propendía por reivindicar el derecho a la libertad, liberando cupos en las cárceles colombianas con miras a restaurar la dignidad humana de los presos (artículo 5). Igualmente, recurriendo a criterios hermenéuticos de interpretación sistemática, se puede observar, cómo en materia de suspensión condicional de la pena (artículo 29) se eliminó el requisito subjetivo que incluso exigía, una valoración de la modalidad y "gravedad" de la conducta punible $^{75}$. También se excluyó la libertad condicional de la prohibición contenida en el artículo 68 A del Código Penal, como operaba con anterioridad a la reforma ${ }^{76}$. Con base en esto nos aventuramos a afirmar que el legislador también quería flexibilizar la concesión de la libertad condicional.

\footnotetext{
${ }^{72}$ Por ejemplo, en providencia del 11 de febrero de 2014, el J.5 E.P.M.S. (Proceso 24949) negó la libertad condicional, con base en la siguiente argumentación: "Si bien es cierto ya ha cumplido con las tres quintas partes de la pena, no se puede desconocer la gravedad de la conducta punible. ( ... ) Frente a este requisito es necesario entrar a analizar la gravedad de la conducta, como fue su comportamiento cuando se cometió el delito. Fuera de la sentencia se valora la gravedad de la conducta, no responsabilidad penal del condenado, no como el resultado de un nuevo proceso de valoración sino de la necesidad del tratamiento penitenciario a causa de la gravedad del comportamiento".

${ }^{73}$ Rolando Robayo (Ex Juez $4^{\circ}$ Penal Municipal con Función de Control de Garantías de Soacha y Ex Juez 2 Penal Municipal de Facatativá - con funciones tanto de garantías como de conocimiento-. Actualmente se desempeña como asistente jurídico del Juzgado 14 de Ejecución de Penas y Medidas de Seguridad de Bogotá).

${ }^{74}$ Entrevista realizada el 6 de marzo de 2014. Se hace reserva del nombre por expresa solicitud del entrevistado.

${ }^{75}$ El numeral 20 del artículo 63 del Código Penal exigía un requisito subjetivo del siguiente tenor: "Que los antecedentes personales, sociales y familiares del sentenciado, así como la modalidad y gravedad de la conducta punible sean indicativos de que no existe necesidad de ejecución de la pena” (Resaltado fuera del texto).

${ }^{76}$ Establecía el artículo 68 A del Código Penal que: "No se concederán los subrogados penales o mecanismos sustitutivos de la pena privativa de libertad de suspensión condicional de la ejecución de la pena o libertad condicional” (Resaltado fuera del texto).
} vol.08, nº.03, Rio de Janeiro, 2015.pp. 1271-1305 1300 
En el derecho comparado encontramos ejemplos como la ley jenna (promulgada en el Estado de New York - 1998) que establecía un requisito objetivo equivalente al 85\% de la pena para los autores, que por primera vez, cometían crímenes violentos, sometiéndolos a una estrecha vigilancia por el período de la libertad condicional (Garland, 2007, p. 218). Incluso en estos casos los sentenciados tienen la posibilidad de acceder a este subrogado.

Todas estas razones llevan a pensar que el obstáculo inicial que consagra el artículo 64 del Código Penal y la aplicación que le han venido otorgando los J.E.P.M.S., no tienen cabida teleológicamente, ya que lo importante respecto a este subrogado, insistimos, es el comportamiento intramuros y no los aspectos antecedentes que determinaron su reclusión y le significaron una pena, acorde con los criterios de dosificación punitiva. Superado este escenario en sede de conocimiento, el J.E.P.M.S. debe velar, ya no por el comportamiento que originó la consecuencia jurídica de la prisión, reiterando que lo trascendental en materia de libertad condicional, no es la conducta punible sino la efectivización de los fines de la pena ${ }^{77}$.

Ahora bien, exigir el pago de la multa para la concesión de subrogados como la libertad condicional y los sistemas de vigilancia electrónica termina siendo discriminatorio y atentatorio del principio constitucional de igualdad, ya que en definitiva, solo quienes tienen facilidades económicas, pueden resultar beneficiados con estos.

Enhorabuena, la Ley 1709 eliminó la exigencia del pago de la multa y los perjuicios como requisito para acceder a la libertad condicional ${ }^{78}$ e igualmente suprimió la exclusión de los delitos consagrados en el artículo $68 \mathrm{~A}^{79}$ del Código Penal ${ }^{80}$, que otrora imposibilitaban en gran medida, acceder a este subrogado penal.

Tampoco debe limitarse in extremo la concesión de estos beneficios frente a determinados delitos, ya que si bien, bajo criterios de prevención general debe enviarse un mensaje a la sociedad sobre la utilidad de la pena y la funcionalidad del sistema judicial, también debe otorgarse una oportunidad al penado para enmendar su camino - prevención especial positiva-, sin convertir la pena en una mera retaliación por el mal causado y procurando efectivizar el fin resocializador de la pena.

De los resultados de esta investigación se puede identificar que el principal factor para la negativa de los mecanismos sustitutivos de la pena de la libertad condicional y los sistemas de vigilancia electrónica corresponde a

\footnotetext{
${ }^{77}$ Cfr. Artículo $4^{\circ}$ del Código Penal.

${ }^{78}$ Ver Gacetas del Congreso Nos. 298 (20-05-13), 668 (02-09-13), 941 (20-11-13) en la exposición relacionada con el "régimen de libertades".

${ }^{79}$ El parágrafo $1^{\circ}$ del artículo 68A del Código Penal consagra que: "Lo dispuesto en el presente artículo no se aplicará a la libertad condicional contemplada en el artículo 64 de este Código, ni tampoco para lo dispuesto en el artículo 38G del presente Código.” (Resaltado fuera del texto).

${ }^{80}$ Tal y como pasaba con anterioridad a la reforma de la ley 1709 de 2014, el artículo 14 del Código Penal argentino excluye algunos delitos del beneficio de libertad condicional: (i) homicidio criminis causa, (ii) abusos sexuales seguidos de muerte, privación ilegitima de la libertad agravada por haber causado intencionalmente la muerte de la víctima, (iii) homicidio con motivo o con ocasión de robo y (iv) secuestro extorsivo seguido de la muerte intencional de la víctima, las cuales tiene pena de prisión perpetua, con excepción de la conducta contenida dentro del literal (iii).
} 
la gravedad de la conducta, la cual - empero-, fue objeto de valoración en la fase de conocimiento al imponerse la sentencia.

También se observa que los sistemas de vigilancia electrónica como sustitutivos de la prisión se han tornado en un mecanismo obsoleto, como ocurría con su consagración pretérita dentro del Código Penitenciario y Carcelario, frente a una cultura judicial de resolución desfavorable a estos pedimentos que incluso ha desincentivado la solicitud de este beneficio. Muy probablemente por esto, fue derogado a través de la ley 1709.

Adicionalmente y relacionado con el objeto principal de la labor propuesta en este ejercicio investigativo, se observa como el pago de la multa en condiciones de insolvencia no era tenido en cuenta por los J.E.P.M.S. BTA. a pesar de la existencia del precedente, salvo lo vislumbrado en el Juzgado $10^{\circ}$ E.P.M.S.BTA. que procuraba por la concesión de libertades, promocionando incluso la figura del cobro coactivo como medida de satisfacción respecto de este requisito.

Sin embargo el principal problema vislumbrado en la investigación traspasa los límites del objetivo específico propuesto y está relacionado con la falta de independencia judicial, situación que imposibilitaría la concesión de estos mecanismos como solución frente al hacinamiento carcelario. Es por esto que los jueces de E.P.M.S.BTA. se valen de los requisitos consagrados en la legislación para negar estos mecanismos sustitutivos, lo que a la postre les representa tranquilidad frente a una eventual investigación disciplinaria que ellos vislumbran inevitable al beneficiar a los condenados con la salida de la cárcel.

Si esta situación se trasponla a la decisión de las medidas de aseguramiento consistentes en detención preventiva en establecimiento carcelario, adoptadas por los Jueces de Control de Garantías y a los Jueces de Conocimiento al decidir la responsabilidad penal de los individuos, no solo continuará afectándose la situación de hacinamiento sino también la legitimidad de los órganos encargados de administrar justicia.

\section{PAYMENT OF THE FINE AND THE LAW 1709 OF 2014. ANALYSIS OF PROBATION AND ELECTRONIC SURVEILLANCE SYSTEMS BEFORE THE LEGISLATIVE TRANSIT}

\section{Abstract}

The paper analyses the situation faced by insolvent convicted people when they are required to pay a bail/pecuniary penalty, in order to be on probation and electronic surveillance as alternative to prison. This requirement was eliminated by law 1709. In particular, I examine if judgments C-185/11 and T-309/12 (Colombian Constitutional Court) are applied in the Execution Bogotá Courts, and their respective corollaries, may provide a solution to prison overcrowding.

Keywords: Convicted insolvent, parole, electronic surveillance, overcrowding. 


\section{BIBLIOGRAFÍA}

ALDERETE, Rubén (2007). La libertad condicional en el código penal argentino, Buenos Aires: LexisNexis

ARBOLEDA, Mario y RUIZ, José Armando (2002). Manual de derecho penal, partes general y especial conforme con el nuevo código penal, Bogotá: Leyer

BARRETO, Antonio (2011). Venturas y desventuras de la regeneración. Apuntes de la historia jurídica sobre el proyecto político de 1886 y sus transformaciones y rupturas en el siglo XX. Bogotá: Universidad de los Andes.

BERNAL, Jaime y MONTEALEGRE, Eduardo (1985). El Proceso Penal, Bogotá: Universidad Externado de Colombia

(1990). El Proceso Penal, Bogotá: Universidad Externado de Colombia

(2002). El Proceso Penal, Bogotá: Universidad Externado de Colombia

(2004). El Proceso Penal, Bogotá: Universidad Externado de Colombia

COLOMBIA, CONGRESO DE LA REPÚBLICA, Diario Oficial No. 46.673 y Gaceta del Congreso 124

(19/04/2007), Leyes 599 de 2000, 906 de 2004, 1142 de 2007, 1098 de 2008, 1453 de 2011 y 1709 de 2014.

COLOMBIA, RAMA JUDICIAL DEL PODER PÚBLICO, CONSEJO SUPERIOR DE LA JUDICATURA, Acuerdo PSAA12-9635 DE 2012 (02-08-12). Por el cual se adoptan medidas de descongestión para los Juzgados de Ejecución de Penas y Medidas de Seguridad de Bogotá

COLOMBIA, RAMA JUDICIAL DEL PODER PÚBLICO, CORTE CONSTITUCIONAL, Sentencias: T162/93, C-212/97, C-087/97, C-358/97, C-592/98, T-213/00, T-528/00, T-1235/01, C-371/02, T-698/02, C-709/02, C-806/02, T-894/02, T-895/02, C-194/05, C-665/05, C-783/05, C-823/05, T-827/05, T-482/06, $\mathrm{T}-865 / 06$ y C-121/12

COLOMBIA, Rama Judicial del Poder Público, Corte Suprema de Justicia, Sala de Casación Penal, providencias del 8 de julio de 2009, proceso 31063, M.P. Jorge Luis Quintero Milanés del 22 de julio de 2011, proceso 36926, M.P.Alfredo Gómez Quintero

CUELLO, Eugenio (1958). La moderna penología, Barcelona: Bosch

DAIEN, Samuel (1947). Libertad condicional, Buenos Aires: Bibliográfica Argentina

ESPITIA, Fabio (2010). Instituciones de derecho procesal penal, sistema acusatorio. Bogotá: Legis

FERRAJOLI, Luigi (1997). Derecho y razón, Madrid: Trotta

FIERRO-MENDEZ, Heliodoro (1998). La libertad provisional y condicional en el derecho procesal penal, Bogotá: Leyer

(2012). Manual de derecho procesal penal. Sistema acusatorio y juicio oral y público, Bogotá: Leyer

FOUCAULT, Michel (1983). Vigilar y castigar. Nacimiento de la prisión, México: Siglo XXI Editores (1998). La verdad y las formas jurídicas, Barcelona: Gedisa 
GARLAND, David (2007). La cultura de las sociedades con altas tasas de criminalidad. Algunas precondiciones de las políticas de seguridad ciudadana. En: Crimen y castigo en la modernidad tardía. Estudio preliminar Manuel A. Iturralde, Bogotá: Siglo del Hombre, Universidad de los Andes y Pontificia Universidad Javeriana.

INPEC. Informe del 31 de enero de 2013. Capítulo "Población internos en Establecimiento de Reclusión y regionales"

JARAMILLO, Jaime (1993). Los archivos y la investigación. En archivos e investigación. Memorias del primer encuentro del sistema nacional de archivos. Medellín: Archivo General de la Nación-Red Departamental de Archivos de Antioquia

JIMENEZ, Enrique (1949). Derecho procesal penal, Volumen II, Madrid: Revista de derecho privado

LOPEZ BARJA, Jacobo (2012). Tratado de derecho procesal penal, Tomo II, Pamplona: Thomson Reutres Arazadi

HERNÁNDEZ, Norberto (2012). Los sistemas de vigilancia electrónica como sustitutivos de la prisión desde una perspectiva analítico-económica del derecho. Bogotá, Universidad Externado de Colombia, Revista Contexto

MARTÍNEZ, Gilberto (1994). Procedimiento penal colombiano, Bogotá: Temis

(1997). Procedimiento penal colombiano, Bogotá: Temis

(2002). Procedimiento penal colombiano, Bogotá: Temis

(2006). Procedimiento penal colombiano, Bogotá: Temis

POSNER, Richard (2002). El análisis económico del derecho. México: Fondo de Cultura Económica

RAMIREZ, Yesid (2005). Sistema acusatorio colombiano. Bogotá: Doctrina y Ley

REYES, Alfonso (1974). Derecho penal, parte general, Bogotá: Universidad Externado de Colombia

ROXIN, Claus (2000). Derecho procesal penal, traducción de Gabriela E. Córdoba y Daniel R. Pastor, revisada por Julio B.J.Maier, Buenos Aires: Editores del Puerto

RUBIO, Mauricio (1996). Crimen sin sumario: análisis económico de la justicia penal en Colombia. Documento CEDE 96-04, Bogotá: Universidad de los Andes

RUIZ, Hoover (1997). Equitipicidad, culpabilidad, preterintención y subrogados penales. Bogotá: Gustavo Ibáñez

RUSCHE, G. y KIRCHHEIMER, O, (1984). Punishment and Social Structure, Columbia University Press, New York, 1939 (traducción al castellano por Emilio García Méndez, Pena y Estructura Social,) Bogotá: Temis

SITUACIÓN CARCELARIA EN COLOMBIA, $99^{\circ}$ período de sesiones, Ginebra, Suiza, Julio de 2010, informe sombra presentado al cdh de naciones unidas, en respuesta al sexto informe de colombia, Presentado por: Grupo de Derecho de Interés Público. Facultad de Derecho. Universidad de los Andes. Bogotá. Colombia. The Carlos A. Costa Immigration and Human Rights Clinic at Florida International University College of Law. United States.

URAZAN, Juan Carlos (2002). Lecciones de derecho procesal penal. Bogotá: Leyer 
URRUTIA, Hernando y CUESTA, Francisco (2008). Sistema penal acusatorio. Audiencias preliminares y juicio oral, teoría y práctica. Tomo II, Bogotá: Ibáñez

(2009). La detención y la prisión domiciliaria y otros mecanismos sustitutivos en el sistema penal acusatorio. Aspectos prácticos. Bogotá: Doctrina y Ley

U.S. SUPREME COURT. Cases: Tate Vs. Short, 401 U.S. 395 (1971) y Williams Vs. Illinois, 399, U.S. 235 (1970)

VELASQUEZ, Fernando (2007). Manual de Derecho penal, parte general, Medellín: Comlibros (2009). Derecho penal, parte general, Medellín: Comlibros

ZAFFARONI, Eugenio (1983). Tratado de derecho penal, Parte General, Volumen V, Buenos Aires: Ediar

Trabalho enviado em 02 de fevereiro de 2015.

Aceito em 24 de março de 2015. 